\title{
Drivers of demand and supply in the Euro interbank market: the role of "Key Players" during the recent turmoil
}

\author{
Caterina Liberati ${ }^{1}$ - Massimiliano Marzo ${ }^{2}$. \\ Paolo Zagaglia $^{3}$ - Paola Zappa ${ }^{4}$
}

\begin{abstract}
We study frictions in trading patterns in the Euro money market. We characterize the structure of lending relations during the period of recent financial turmoil. We use a network-topology method on data from overnight transactions in the Electronic Market for Interbank Deposits (e-MID) to investigate two main issues. First, we characterize the roles of borrowers and lenders in long-run relationships by providing evidence on network formation at a 3-month frequency. Second, we identify the "key players" in the marketplace and study their behavior. In our formalization, key players are "locally-central banks" within a network that lend (or borrow) large volumes to (from) several counterparties, while borrowing (or lending) small volumes from (to) a small number of institutions. Our results are twofold. We show that the aggregate trading patterns in e-MID are characterized by largely asymmetric relations. This implies a clear difference in the roles of lenders and borrowers, with market positions changing
\end{abstract}

Paolo Zagaglia

paolo.zagaglia@unibo.it

Caterina Liberati

caterina.liberati@unimib.it

Massimiliano Marzo

massimiliano.marzo@unibo.it

Paola Zappa

paola.zappa@usi.ch

1 Department of Economics, Statistics and Management, Università degli Studi Milano-Bicocca, Milan, Italy

2 Department of Economics, Università di Bologna, Bologna, Italy

3 Department of Cultural Goods (Ravenna Campus), Intentac, Rimini Centre for Economic Analysis, Università di Bologna, Bologna, Italy

4 Faculty of Economics, University of Italian Switzerland, Lugano, Switzerland 
only gradually over time. We also find that the large net lenders exploit their positions as network leaders by imposing aggressive pricing policies on their counterparties.

Keywords Market microstructure - Network analysis · Money markets · Money supply

JEL Classification $\quad \mathrm{D} 85 \cdot \mathrm{G} 01 \cdot \mathrm{G} 10 \cdot \mathrm{G} 21$

In the no-holds barred world of trading over-the-counter derivatives in the interbank market, traders and brokers view themselves as combatants in a professional market, where you lose one day, but can win the next... The industry is reluctant to fully automate OTC trading because it would result in a more open and transparent market and erode the informational advantages of the big dealers. Smaller banks have little choice but to abide by the rules.

MacKenzie (2012)

\section{Introduction}

Money market transactions are one of the key funding vehicles for financial institutions. The structure of the market comprises a primary provider of money, namely, the central bank, as well as many other banks lending to each other. The centrality of the money market was noted during the recent financial turmoil, which erupted in August 2007 in the form of a freeze on interbank lending (see Holthausen and Pill 2010). This event demonstrated that a lockup of interbank activity has systemic implications for all asset markets (see Holthausen and Pill 2010). Therefore, understanding trading patterns in the interbank market is crucial for evaluating its functioning both during normal conditions and during times of stress.

The interbank market has been characterized as a network of exchange, where banks are nodes and cash flows denote ties (see, e.g., Iori et al. 2008). Many papers use network-topology methods to study linkages between banks (see, e.g., Bech and Atalay 2008; Iazzetta and Manna 2009a), and the impact of these networks on demand for and supply of cash (see, e.g., Soramaki et al. 2006). Most studies focus on describing short-term bank behavior, thus studying issues of price volatility (see, e.g., Cassola and Morana 2010) and the impact of policy measures (see, e.g., Durreé and Nardelli 2008). ${ }^{1}$

The literature shows that interbank markets are often organized as core-periphery structures (see, e.g, Soramaki et al. 2006). This means that money markets are characterized by "locally-central" banks that are closely connected, and on which all the other banks depend for the distribution of cash. In this paper, we provide empirical evidence on the role played by "money centers" (see Craig and von Peter 2014) in an unsecured segment of the Euro money market, the so-called Electronic Market for Interbank Deposits (e-MID).

\footnotetext{
1 Recent contributions focus on the systemic implications of funding risk, namely, the risk that a bank's shortage of cash may spill over into the entire financial system (see, e.g., Drehmann and Tarashev 2011).
} 
The e-MID platform provides a transparent and non-anonymous market. The way exchanges are organized allows market participants to differentiate with regard to counterparty characteristics, and to evaluate past trading behavior. Thus, a bank's reputation is a key factor in the establishment and maintenance of lending relations. ${ }^{2}$ Our dataset covers the period of the recent financial turmoil (between 2006 and 2009), during which reputational effects were strengthened.

Our preliminary investigation of the data indicates that aggregate trading patterns in e-MID are characterized by largely asymmetric relations in each network, implying that there are clearly different roles played by lenders and borrowers. To put it more clearly, there are institutions that exercise strong control on either the supply or the demand side of the market.

We propose a methodology for identifying what we call "key players". Key player banks lend (borrow) large amounts of cash to many counterparties, while borrowing (lending) small amounts from (to) a small group of banks. In short, these key players are the driving forces behind demand and supply in the market.

Key players are especially important in networks with an asymmetric structure because they have the power to create a bottleneck in the distribution of cash. This may arise as the by-product of the central nodes' "market power". 3 The question of interest is whether this feature benefits the key players. In other words, we would like to understand whether key players exploit their leading position by demanding higher (lower) lending (borrowing) interest rates than the market average.

The analysis of key players reveals two main empirical facts. We show that the composition of the group of key players - both for the supply and the demand sidehas changed every year since 2006. This indicates that e-MID is not comprised of market players with medium- or long-term trading strategies. Rather, banks' patterns of exchange appear contingent on short-term developments. In terms of pricing policies, key players exploit their market position. Specifically, we find statistical evidence suggesting that the big lenders charge interest rates above market average.

The results presented in this paper differ from those in the literature in several respects. For example, the existent literature argues that size matters in the interbank market. Gabrieli $(2009,2012)$ shows that larger European banks enjoyed a significant reduction in overnight rates after the Lehman Brothers bankruptcy. This is the socalled too-big-to-fail guarantee that larger banks have enjoyed ever since European governments promised not to let fail any systemically important institution. Angelini et al. (2011) study the spread between uncollateralized rates and Eurepo rates on term contracts. Their results corroborate the findings of Gabrieli (2009, 2012).

We provide an exact identification of which banks drive the buy and sell side of the market using the identifiers provided in our dataset. Unlike Fricke and Lux (2015), we refrain from estimating models of network structure, which may then be used to

\footnotetext{
2 The role of market reputation is also stressed by Idier and Nardelli (2011) in the context of over-the-counter segments of the Euro interbank market.

3 The issue of market power in financial networks is also investigated by Kraenzlin and von Scarpatetti (2011), who study the price setting behavior in the Swiss Franc repo market during the turmoil period. They find that banks use both their market power and private information to offer different lending rates depending on the characteristics of their counterparties.
} 
identify the "core" banks. Rather, we build on economic intuition, and propose an empirical strategy that is free from tight modeling assumptions. Hence, our strategy for identifying key players takes into account — and encompasses - the core-periphery structure documented by Fricke and Lux (2015). Our empirical strategy also allows to evaluate the cross section of the pricing effect of key players.

Our analysis provides relevant economic insights for the ECB's money supply policy. The asset exchanged in the interbank market is very different in nature from other "standard" assets. Banks need cash to carry out their daily operations. However, due to market polarization of roles, a small group of banks controls how the cash provided by the ECB is distributed throughout the interbank market. This suggests that changes in the interbank rates alone are not an appropriate indicator of the success of a loose money supply policy, an especially relevant issue in the context of the recent market turmoil. In fact, during this period, the ECB implemented several extraordinary money supply operations with the aim of easing tensions in the market (see Lenza et al. 2010). Another relevant finding is that the market role played by large net lenders may create conditions for "distortions" or inequality in access to cash across the demand side, which may directly and negatively affect the ECB's money supply policy in times of stress.

The paper is organized as follows. Section 2 contains a literature review. Section 3 describes the information available in our dataset. Section 4 provides a descriptive analysis of the data. Section 5 describes our approach to network analysis. Section 6 presents the main patterns of the networks that provide the foundation for our study of key players. Section 7 discusses our methodology for identifying the largest net lenders or borrowers in each network. Section 8 discusses key player characteristics. Section 9 concludes.

\section{Literature overview}

The literature on Euro area money markets suggests that the prevailing patterns of exchange are characterized by asymmetries in the distribution of cash. It thus appears that a small subset of banks is playing a disproportionately large role in the market, which both justifies and makes our study relevant.

The empirical results suggest that e-MID is comprised of local structures with hierarchical relations, core-periphery structures, and clusters. Iori et al. (2008) show that the number of vertical links in the trading networks is heavy tailed, which suggests that a few banks trade with many counterparties. De Masi et al. (2006) find that banks build subgroups of trading partners to which they lend persistently. This indicates that interbank lending has a propensity to cluster. e-MID is also characterized by a stable core-periphery structure, whereby the "core" banks are both borrowers and lenders (see Fricke and Lux 2015). The core-periphery is asymmetric, as the "core" borrowers engage in more trading activity than do the "core" lenders.

Our contribution is also related to recent analyses of relationship lending in the money market. By our definition, key players trade with many banks. In this sense, they can be thought of as "preferential" net lenders or borrowers, as they choose their 
counterparties and are, in turn, chosen as counterparties. ${ }^{4}$ The role of preferential relations in the money market is widely documented (see, e.g., Craig et al. 2013). The literature, however, tends to focus on the pricing implications of these relationships. Cocco et al. (2009) find that banks pay lower borrowing rates within their network of relations, and trade with counterparties that face uncorrelated money-demand shocks. Fecht et al. (2011) provide a study of the role of stable connections in the German money market. Their empirical results indicate that banks operating in formal networks do not enjoy any preferential price treatment. Stable relations between banks do not necessarily lead to borrowing rates that are lower than average. Rather, preferential pricing appears correlated with the ability of an institution to avoid a net "squeeze" vis-à-vis the aggregate money supply. Raddant (2014) identifies preferential lending relationships in e-MID by studying the discounts offered against average lending rates. The author shows that banks tended to borrow at a slight discount before the Lehman bankruptcy. In the following period, borrowers with large net exposures paid a premium on top of the average market rate.

What explains the rise and persistence of key players? The literature reveals two important characteristics of the Euro money market that may help answer this question. The first involves the institutional rules governing private banks' access to the primary supply of cash at the ECB. The second involves asymmetric information in e-MID.

Can the institutional organization of the money market lead to the emergence of key players? Idier and Nardelli (2011) suggest that this is indeed the case. They point out that the rules for taking part in ECB tenders have a discriminatory character. Specifically, private banks can take part in liquidity operations only if they are listed as eligible counterparties by the ECB. In addition, banks face substantial administrative costs when taking part in ECB tenders, which can prove a disincentive, especially for smaller banks. Idier and Nardelli (2011) provide empirical evidence suggesting that trading in the uncollateralized segment of the overnight interbank market is affected by asymmetric information among counterparties. Moreover, certain banks are not constrained by compulsory reserve requirements. These institutions engage in significant trading activity. They can collect and exploit information about the aggregate liquidity imbalance that smaller banks cannot. In other words, these studies hint at a relationship between bank financial strength, trading propensity, and superior information about the market. 5

In this paper, we identify as key players those banks that lend/borrow large amounts of cash from many counterparties. There are thus two main features that characterize the key players: engagement in stable networks of market relations and quantitatively relevant lending/borrowing activity. We design both our data handling and key-player detection methodology based on these characteristics.

\footnotetext{
4 Iori et al. (2014) suggest that "preferential" trading is related to the "memory" of transactions. Hence, the more often a bank has lent to a counterparty, the more likely it is that it will lend again to that borrower.

5 Babus (2006) characterizes the information leading to network formation as information about counterparty risk, or "risk of contagion". The author provides a theoretical model suggesting that banks minimize the tradeoff between the costs and benefits of creating a network by choosing partners resilient to contagion from adverse shocks. Thus, an equilibrium network has a contagion probability equal to zero. In addition, the banks outside the network face credit rationing from part of the network components.
} 
Craig and von Peter (2014) provide an insightful empirical study on the role of "centers" in the distribution of cash. They use data on German banks to show that these institutions lend to each other through core-periphery structures. Specifically, these institutions have a preference for supplying cash through the intermediation of 'locally-central' banks, with which they already have a lending relationship. The centrality of banks is largely correlated to their idiosyncratic characteristics. Banks with large balance sheets tend to occupy central positions in the network. Overall, these findings support our strategy for identifying key players.

\section{The dataset}

We investigate the Electronic Market for Interbank Deposits (e-MID). Transactions in this marketplace operate through an electronic platform that is fully centralized and operates in Milan. The market has several peculiar characteristics. The first is that it consists of two submarkets, and, consequently, there are two types of transactions, each of which follows different rules. In the "ask" (or buy) market, the transaction is started by the borrower - that is, the aggressor-who borrows cash from the lender -that is, the quoter-. In the "bid" (or sell) market, the transaction is initiated by the lender (i.e., the aggressor) who lends to the borrower (i.e., the quoter). Transactions in e-MID involve money exchange at various maturity structures, ranging from overnight to 11 months. However, most of the trades involve overnight maturity contracts. Banks can choose their trading counterparty, whereas the information on rates and amounts is made public. In addition, the minimum trade size is established a priori.

The information available distinguishes between regular size transactions, for which the minimum involved is 1.5 million euros, and large transactions, for which the minimum involved is 100 million euros. For each transaction executed through the system, a record is produced that provides information on the identity of the aggressor and the quoter, the amount traded, the interest rate, the date and time of delivery, and the loan length and type. Because of privacy concerns, each e-MID member is identified by a unique six-digit code, the first two digits signifying country of origin and the following four a 0001 to nnnn code. This system allows determining the nationality of a bank, but not its identity.

Table 1 reports some key statistics on the number of trading banks and trades. It shows that our sample contains 305,489 overnight "ask" and "bid" events taking place between January 1, 2006 and December 31, 2009. Since the overwhelming majority of interbank market activity involves overnight transactions, we exclude longer duration trades from the sample.

\section{The organization of lending-borrowing relations: a descriptive outline}

An important issue in analyzing money market transactions is defining the time unit over which to observe market properties. Several studies document changes in the money market at a daily frequency to discover how money exchanges occur in the short term (see, e.g., Brunetti et al. 2011). However, this strategy does not suit the 
Table 1 Number of banks and trades

\begin{tabular}{llllll}
\hline Year & Quarter & $N$ banks & $N$ trades & $N$ ON trades & $\%$ ON trades \\
\hline 2006 & 1 & 170 & 30,230 & 23,068 & 76.308 \\
& 2 & 170 & 30,130 & 22,979 & 76.266 \\
& 3 & 171 & 29,502 & 22,328 & 75.683 \\
2007 & 4 & 173 & 28,684 & 21,993 & 76.673 \\
& 1 & 171 & 27,747 & 21,083 & 75.983 \\
& 2 & 171 & 26,622 & 20,047 & 75.302 \\
& 3 & 172 & 29,332 & 23,738 & 80.928 \\
2008 & 4 & 171 & 26,889 & 21,579 & 80.252 \\
& 1 & 170 & 25,156 & 20,725 & 82.385 \\
& 2 & 169 & 25,428 & 20,612 & 81.060 \\
& 3 & 165 & 22,856 & 18,582 & 81.300 \\
2009 & 4 & 150 & 19,627 & 16,012 & 81.581 \\
& 1 & 145 & 16,612 & 14,354 & 86.407 \\
& 2 & 147 & 16,312 & 14,150 & 86.545 \\
& 3 & 124 & 13,959 & 12,550 & 89.906 \\
& 4 & 132 & 16,132 & 14,087 & 87.323 \\
\hline
\end{tabular}

purposes of our contribution. ${ }^{6}$ As stressed by Finger et al. (2013), exchange relations in the interbank market cannot typically be observed at a given point in time but have to be approximated by aggregating trades. Finger et al. (2013) also show that aggregation over a sufficiently long time horizon might reveal a non-random structure for longlasting relationships. Building on their results, we aggregate our data over a quarterly frequency. This choice also takes into account the key patterns emerging from the data. Table 2 reports the Spearman's rank correlation coefficients computed per pairs of quarters for the net traded volumes. ${ }^{7}$ The resulting figures confirm that using a quarterly dataset is appropriate for our study. The values of the correlation computed for two consecutive periods are never lower than 0.719 , hinting at substantial stability in trading behavior over a quarterly frequency.

The 2007 turmoil had several impacts on e-MID transactions. Table 1 shows the number of market participants and the number of transactions. Both figures have decreased over time. ${ }^{8}$ The number of banks active on at least one side of the market is around 170 until the first quarter of 2008 . The highest market participation occurs in the

\footnotetext{
${ }^{6}$ Specifically, we are interested in identifying the market structure-i.e., discovering the existence of stable relationships among pairs or subgroups of banks, detecting the persistence of roles, and interpreting our results in light of the turmoil.

7 The net traded volume distribution is obtained as the difference between volumes lent and volumes borrowed per bank.

8 There are banks that join or leave the system at different points in time. Across the sample period, the total number of actors operating in e-MID is 194.
} 
Table 2 Spearman's rank correlation coefficients per pair of quarters for net traded volumes

\begin{tabular}{llll}
\hline & Corr I-II quarter & Corr II-III quarter & Corr III-IV quarter \\
\hline 2006 & 0.788 & 0.825 & 0.786 \\
2007 & 0.878 & 0.734 & 0.778 \\
2008 & 0.876 & 0.755 & 0.723 \\
2009 & 0.874 & 0.749 & 0.719 \\
\hline
\end{tabular}

The correlation coefficients are all significant at the 0.05 level

fourth quarter of 2006, after which the number of participating institutions drops. The lowest number of banks (124) is observed in the third quarter of 2009. Similar patterns can be seen in the number of trades. Interestingly enough, the percentage of overnight trades has become a progressively more significant part of overall trades since the third trimester of 2007, revealing a higher propensity of banks toward short-term loans.

Finally, the size of trades also changed noticeably after the turmoil began. In the first panel of Table 3, we report some selected statistics on traded volumes. The freeze in market activity that characterizes the turmoil period is reflected by the decrease in total volume traded, which drops by $14 \%$ from 2006 to 2007, by $20 \%$ from 2007 to 2008 , and by about $40 \%$ from 2008 to 2009 . The decrease in average volumes from 25,866 in the second trimester of 2006 to 15,450 in the third trimester of 2009 paints a similar picture. The decreasing trend becomes sharper after the third quarter of 2008.

The patterns in volumes traded affect the evolution of lending rates over the sample period. The second panel of Table 3 reports some statistics on the interbank interest rates. Both the mean and the median rates rose steadily from the beginning of the observation period (i.e., the average interest rate was 2.398 in the first quarter of 2006) to the beginning of the financial crisis (i.e., the average interest rate was 4.218 - the highest value observed-in the third quarter of 2008). In contrast to the findings on traded volumes, this evidence signals that the market had started raising interest rates long before the turmoil period begun. From the third quarter of 2008, then, the market freeze led to a consistent drop in interest rates, hitting a low of 0.299 in the third trimester of 2009.

Changes in the behavior of e-MID participants deserve attention. Table 4 reports some descriptive statistics on volumes lent and borrowed per bank. In each period, only a fraction (though high) of the banks active in e-MID operate on both sides of the market. The share of lenders is high (with a maximum of $93.7 \%$ of the total number of banks) and almost constant in the first 3 years of the observation period. Then, this number drops during 2009, reaching its lowest point $(83.3 \%)$ in the fourth trimester of that year. The share of borrowers reaches a peak of $86.3 \%$ in the third quarter of 2006; a low of $73 \%$ is observed in the second quarter of 2009.

These statistics indicate that e-MID is comprised of financial institutions that focus on lending activities, banks devoted mostly to borrowing, and banks operating on both sides of the market. In short, e-MID appears to be a market in which banks with diverse dominant roles co-exist. Additional evidence for this is obtained by observing standard deviations of the distributions of deposits (both lent and borrowed) per bank. 
Table 3 Selected average statistics on traded volumes and interest rates

\begin{tabular}{|c|c|c|c|c|c|}
\hline Year & Quarter & 1 & 2 & 3 & 4 \\
\hline \multicolumn{6}{|c|}{ Volumes } \\
\hline \multirow[t]{6}{*}{2006} & Mean & 25.125 & 25.867 & 24.965 & 22.582 \\
\hline & Median & 15 & 15 & 15 & 12 \\
\hline & Min & 0.050 & 0.050 & 0.100 & 0.050 \\
\hline & Max & 500.000 & 500.000 & 500.000 & 500.000 \\
\hline & Sum & 579586.340 & 594392.460 & 557422.510 & 496636.840 \\
\hline & Std dev & 29.619 & 33.389 & 32.344 & 28.619 \\
\hline \multirow[t]{6}{*}{2007} & Mean & 23.223 & 22.944 & 21.968 & 20.284 \\
\hline & Median & 12.500 & 13.000 & 11.000 & 10.000 \\
\hline & Min & 0.100 & 0.100 & 0.050 & 0.060 \\
\hline & Max & 600.000 & 980.000 & 600.000 & 850.000 \\
\hline & Sum & 489614.460 & 459956.790 & 521465.090 & 437707.900 \\
\hline & Std dev & 32.249 & 31.230 & 31.873 & 34.398 \\
\hline \multirow[t]{6}{*}{2008} & Mean & 19.547 & 20.888 & 20.091 & 18.847 \\
\hline & Median & 10 & 10 & 10 & 10 \\
\hline & Min & 0.100 & 0.050 & 0.050 & 0.300 \\
\hline & Max & 1000.000 & 1050.000 & 700.000 & 1000.000 \\
\hline & Sum & 405109.340 & 430543.410 & 373334.620 & 301774.060 \\
\hline & Std dev & 33.335 & 29.096 & 26.512 & 30.943 \\
\hline \multirow[t]{6}{*}{2009} & Mean & 16.444 & 18.602 & 15.450 & 19.267 \\
\hline & Median & 10.000 & 10.000 & 10.000 & 10.000 \\
\hline & Min & 0.300 & 0.450 & 0.050 & 0.250 \\
\hline & Max & 200.000 & 600.000 & 450.000 & 1000.000 \\
\hline & Sum & 236035.410 & 263223.960 & 193894.120 & 271419.960 \\
\hline & Std dev & 18.876 & 22.596 & 17.755 & 26.308 \\
\hline \multicolumn{6}{|c|}{ Interest rates } \\
\hline \multirow[t]{5}{*}{2006} & Mean & 2.398 & 2.628 & 2.928 & 3.363 \\
\hline & Median & 2.345 & 2.605 & 3.000 & 3.325 \\
\hline & Min & 1.100 & 1.450 & 1.720 & 2.200 \\
\hline & Max & 2.680 & 2.970 & 3.160 & 3.820 \\
\hline & Std dev & 0.129 & 0.127 & 0.137 & 0.150 \\
\hline \multirow[t]{5}{*}{2007} & Mean & 3.601 & 3.850 & 4.077 & 3.943 \\
\hline & Median & 3.570 & 3.830 & 4.070 & 4.005 \\
\hline & Min & 2.450 & 2.700 & 2.000 & 1.500 \\
\hline & Max & 4.300 & 4.310 & 5.000 & 4.700 \\
\hline & Std dev & 0.152 & 0.172 & 0.216 & 0.173 \\
\hline
\end{tabular}


Table 3 continued

\begin{tabular}{llllll}
\hline Year & Quarter & 1 & 2 & 3 & 4 \\
\hline \multirow{2}{*}{2008} & Mean & 4.040 & 3.971 & 4.218 & 3.061 \\
& Median & 4.030 & 3.990 & 4.280 & 3.120 \\
& Min & 2.600 & 2.700 & 2.800 & 1.870 \\
& Max & 4.500 & 4.500 & 4.800 & 5.100 \\
& Std dev & 0.095 & 0.126 & 0.207 & 0.587 \\
& Mean & 1.234 & 0.668 & 0.329 & 0.299 \\
& Median & 1.150 & 0.700 & 0.300 & 0.290 \\
& Min & 0.470 & 0.180 & 0.180 & 0.180 \\
& Max & 2.600 & 1.700 & 0.850 & 0.750 \\
& Std dev & 0.394 & 0.237 & 0.077 & 0.057 \\
\hline
\end{tabular}

Traded volumes are expressed in million Euros

The high dispersion of the data with respect to the average indicates rather different approaches to trading.

The volume traded distributions reveal an important fact, and one that is the starting point for further analysis in this paper: there is a high concentration of banks on both the lending and the borrowing side. At the beginning of the observation period, 10 banks, most of which are Italian, are responsible for $39.71 \%$ of the total volume lent. This percentage remains almost constant over time: it drops to $37.51 \%$ in the third trimester of 2007, rises again to a maximum of $43.37 \%$ in the second quarter of 2008 , and finally decreases to $40.86 \%$ at the end of the observation period. A similar picture emerges for the demand for deposits. On this side of the market, however, the level of resource concentration is stronger and the trend slightly more unstable. The first 10 banks - again, all of Italian - account for $61.08 \%$ of the market at the beginning of 2006 and for $73 \%$ - the highest value - at the end of 2009, with a minimum of $51.84 \%$ in the first quarter of 2007. As discussed thoroughly by the ECB (2010), the nationality of market participants plays a key role in e-MID. The counterparties belong to 16 different countries, with Italian banks the largest group of institutions. The weight of Italian banks in e-MID increases over time, as an increasing number of foreign banks leaves the market. Statistics not reported in the interest of brevity point to a division of roles across nationalities, with French, Greek, and Dutch banks mostly lending, and British banks mostly borrowing.

\section{Aspects of data handling and methods for network analysis}

To analyze the structure of the money market and detect individual behavior, we use methods from social network analysis (SNA) (see, e.g., Wasserman and Faust 1994; Carrington et al. 2005; Borgatti et al. 2009). This framework has been applied in many contexts, ranging from the study of interpersonal relations to inter-organizational dynamics. With regard to relationships among banks, SNA has proven effective in examining the topological properties of the money market (see De Masi et al. 2006; 
Table 4 Selected average statistics on cash volumes lent and borrowed
The figures reported here are expressed in million Euros

\begin{tabular}{|c|c|c|c|c|}
\hline Year & Quarter & $\%$ Banks & Mean & Std dev \\
\hline \multicolumn{5}{|c|}{ Amount lent } \\
\hline \multirow[t]{4}{*}{2006} & 1 & 0.913 & 3969.769 & 6532.446 \\
\hline & 2 & 0.890 & 4099.258 & 7623.740 \\
\hline & 3 & 0.925 & 3741.091 & 7278.590 \\
\hline & 4 & 0.896 & 3378.482 & 5462.841 \\
\hline \multirow[t]{4}{*}{2007} & 1 & 0.929 & 3376.651 & 5568.977 \\
\hline & 2 & 0.880 & 3309.042 & 5465.255 \\
\hline & 3 & 0.937 & 3499.766 & 5718.777 \\
\hline & 4 & 0.919 & 3194.948 & 5133.523 \\
\hline \multirow[t]{4}{*}{2008} & 1 & 0.917 & 3045.935 & 4775.071 \\
\hline & 2 & 0.897 & 3311.872 & 5264.287 \\
\hline & 3 & 0.921 & 2894.067 & 4442.886 \\
\hline & 4 & 0.882 & 2694.411 & 4808.469 \\
\hline \multirow[t]{4}{*}{2009} & 1 & 0.867 & 2126.445 & 3000.817 \\
\hline & 2 & 0.881 & 2371.387 & 3354.567 \\
\hline & 3 & 0.917 & 1958.526 & 2480.658 \\
\hline & 4 & 0.833 & $2,467,454$ & $3,048,374$ \\
\hline \multicolumn{5}{|c|}{ Amount borrowed } \\
\hline \multirow[t]{4}{*}{2006} & 1 & 0.794 & 4563.672 & 10229.864 \\
\hline & 2 & 0.804 & 4537.347 & 9652.734 \\
\hline & 3 & 0.863 & 4010.234 & 10273.038 \\
\hline & 4 & 0.799 & 3791.121 & 7971.481 \\
\hline \multirow[t]{4}{*}{2007} & 1 & 0.808 & 3885.829 & 8146.682 \\
\hline & 2 & 0.804 & 3621.707 & 7191.813 \\
\hline & 3 & 0.742 & 4419.196 & 8316.538 \\
\hline & 4 & 0.832 & 3529.902 & 6610.083 \\
\hline \multirow[t]{4}{*}{2008} & 1 & 0.752 & 3716.599 & 7003.744 \\
\hline & 2 & 0.779 & 3810.119 & 7496.590 \\
\hline & 3 & 0.771 & 3456.802 & 7232.545 \\
\hline & 4 & 0.748 & 3176.569 & 6178.868 \\
\hline \multirow[t]{4}{*}{2009} & 1 & 0.758 & 2433.355 & 5138.561 \\
\hline & 2 & 0.730 & 2861.130 & 6064.351 \\
\hline & 3 & 0.750 & 2393.755 & 4642.110 \\
\hline & 4 & 0.750 & $2,741,616$ & $3,048,374$ \\
\hline
\end{tabular}

Iori et al. 2008; Hatzopoulos et al. 2013) and in assessing the resilience of the banking system to financial crises and risks of contagion (Markose et al. 2009).

In this paper, we use SNA to assess the stability of network relations and to identify the most important actors in such networks. Building on previous studies (see, e.g., Iori et al. 2008), the transactions are represented as a network $N(V, E)$. The network nodes $V$ are the banks, and ties $E$ are identified as the money lent from one institution to another. Aggressors and quoters are reclassified as lenders and receivers 
(or the opposite, depending on the submarket explored) based on cash flow direction. Therefore, we assume that a tie exists from bank $i$ to bank $j$ when $i$ lends money to $j$, independent of the origin of the transaction (i.e., whether the transaction is an "ask" or a "bid"). We have the following two cases:

1. For bid transactions, the tie goes from the aggressor (lender) to the quoter (receiver).

2. For ask transactions, the tie goes from the quoter (lender) to the aggressor (receiver).

Since the tie from $i$ to $j\left(e_{i j}\right)$ is different from the tie from $j$ to $i\left(e_{j i}\right)$, the network is defined as "directed". To each tie, we attach a weight $w_{i j}$ that represents the amount of money that $i$ lends to $j$ over a given time span.

We computed the weight $w_{i j}$ as the 3-month amount lent from $i$ to $j$. Formally:

$$
w_{i j}=\sum_{z=1}^{H} t_{i j z}
$$

where $t_{i j z}$ is the amount of the transaction $z$ from $i$ to $j$ per 3-month time window, and $H$ denotes the number of transactions from $i$ to $j$ per 3-month time window. Then, we build 16 networks, one for each period. Each network corresponds to an asymmetric adjacency matrix $W$ of size $n \times n$ whose generic element is $w_{i j}(i=1, \ldots, n ; j=$ $1, \ldots, n ; i=j)$.

The analysis is performed on two levels. First, we consider the full structure of transactions at the network level for each period. This analysis is intended to provide some general insight into the interaction among banks and verify the existing of a network structure, thus justifying further investigation. We then shift our focus to the role played by banks in the network. This second level of analysis leads to the identification of market inefficiencies or bottlenecks, that is, the existence and persistence over time of banks that control the supply or demand of deposits in the market. Their behavior and pricing policies are then studied in detail. We repeat this process for each of the 16 quarterly networks to have some insight into the stability of long-term network relations over time. ${ }^{9}$ Also, this analytic framework allows us to shed light on how various phases of the turmoil affected the market behavior of e-MID participants.

\section{Measures of network activity}

\subsection{Results from network-level analysis}

In this section, we study the entire network structure with the purpose of detecting preferential trading patters. We also investigate how these patterns changed during the turmoil period.

\footnotetext{
9 To run the analysis, we use the software packages sna (see Butts 2008, 2010), igraph (see Csardi and Nepusz 2006), and tnet (see Opsahl 2011), developed within the R statistical computing environment and specifically designed for network studies.
} 


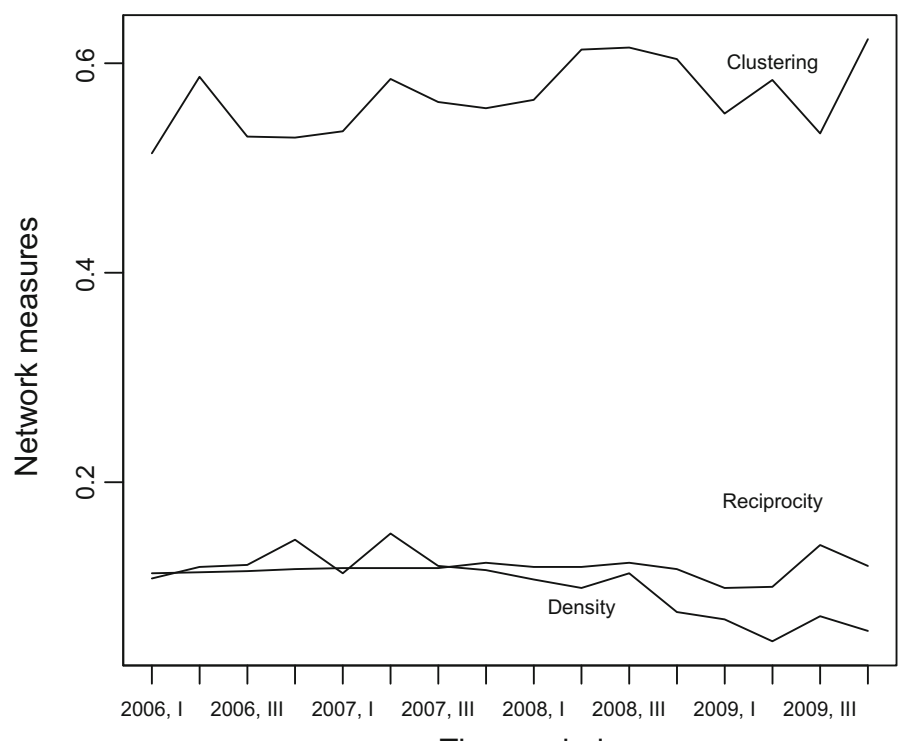

Time periods

Fig. 1 Descriptive network measures

We compute relevant measures of network activity. Network density is the most basic descriptive index. Density is the proportion of possible ties that are actually present in the network to the maximum possible; that is, a measure of completeness. Formally, in the case of a directed network, the density $\Delta$ is computed as follows (see Wasserman and Faust 1994):

$$
\Delta=\frac{L}{n(n-1)}
$$

The term $L$ denotes the number of ties in the empirical network. Since a directed tie can be seen as an ordered pair of nodes, there are $n(n-1)$ possible ties. The density coefficient ranges between 0 (no ties are present) and 1 (all ties are present).

The results are reported in Fig. 1. In our network, density is moderate (it ranges from 0.10 to 0.14 ) and almost constant over time. A slight decrease is observed in the third quarter of 2007 and again in the third quarter of 2008. Overall, the density values indicate that the network is sparse; less than $15 \%$ of the possible ties among the banks actually exist. Although all the banks can participate in trading, this value signals that only a fraction of them are actually active and/or selected as counterparties (see Fig. 2).

Reciprocity focuses on the relationship between pairs of nodes. It identifies a mutual exchange of money between pairs of banks. Therefore, it implies the existence of a non-hierarchical relationship among actors. A node pair $(i, j)$ is called "reciprocal" if there are ties between both parties in both directions. Hence, the reciprocity of a directed network is the proportion of all possible $(i, j)$ pairs that are reciprocal, provided there is at least one tie between $i$ and $j$. Like density, the reciprocity index varies between 0 and 1 : 
(a) 2006, quarter $=\mathrm{I}$

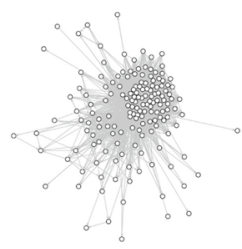

(e) 2007, quarter=I

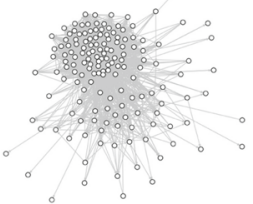

(i) 2008, quarter=I

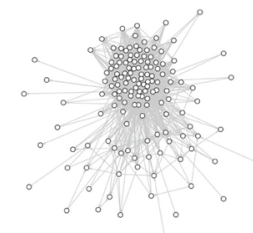

(m) 2009, quarter=I

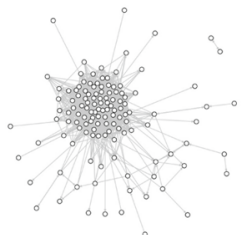

(b) 2006, quarter=II

(c) 2006, quarter=III

(d) 2006, quarter=IV

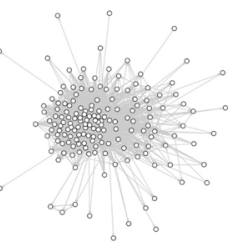

(f) 2007, quarter=II

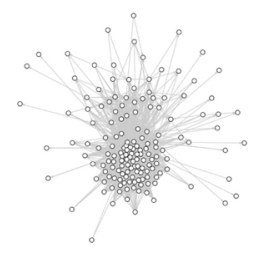

(j) 2008, quarter=II

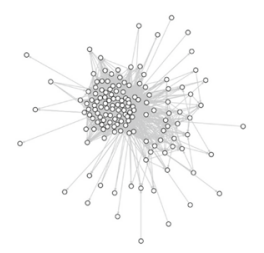

(n) 2009, quarter=II

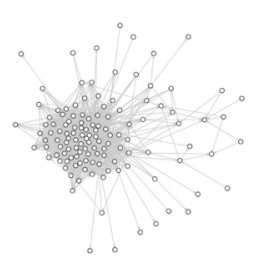

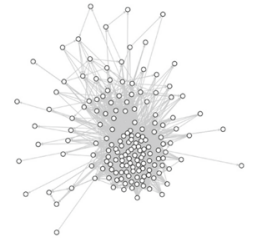

(g) 2007, quarter=III

(h) 2007, quarter=IV

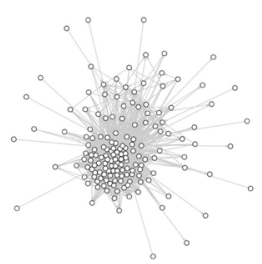

(k) 2008, quarter=III

(I) 2008, quarter=IV

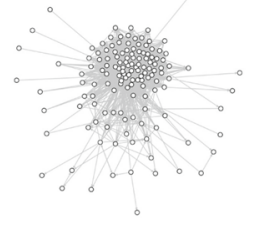

(o) 2009, quarter=III

(p) 2009, quarter=IV

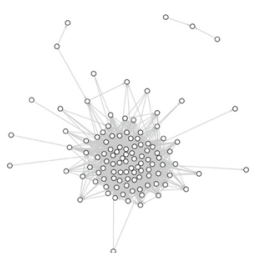

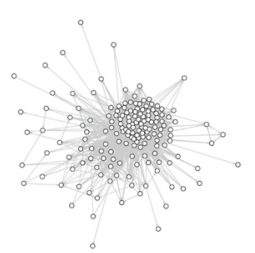
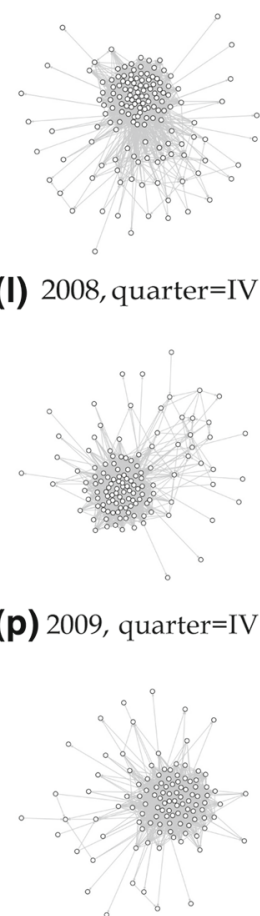

Fig. 2 Networks of lending-borrowing relations. Legend: the white circles denote banks and the gray lines denote directed ties between pairs of them

$$
\mathrm{r}=\frac{\sum_{i j} e_{i j} e_{j i}}{L}
$$

The values of the reciprocity index for e-MID are very low and point to a lack of bidirectional exchange between banks. The percentage of reciprocal dyads is always lower than $15 \%$ and declines significantly over time. It is equal to $10.80 \%$ in the first period of 2006, increases to $15.10 \%$ in mid 2007, and then decreases almost steadily to $5.80 \%$ by the end of 2009 . This indicates a tendency toward asymmetric relations that becomes stronger over time. In other words, there seems to be a strong and increasing 
distinction of roles in e-MID when shifting from stability to financial crisis. Indeed, this tendency emerges as soon as the turmoil starts.

Finally, the clustering effect studies the network's degree of interconnectedness and the structural embeddedness of its nodes. In organizational studies, embeddedness is interpreted as the overwhelming presence of links, which fosters both trust and cooperative behavior. Also, embeddedness and closure reduce uncertainty and information asymmetry between two actors. The clustering coefficient examines relations involving three nodes and measures the tendency of nodes to cluster into tightly knit groups. A positive clustering coefficient, therefore, implies an increase in the likelihood that two nodes will be connected if they share a common acquaintance. We apply the specification of clustering coefficient proposed by Opsahl and Panzarasa (2009), that is, the generalized global clustering coefficient. It is defined as the number of closed triplets (i.e., three nodes connected by three ties) over the total number of triplets. Also, it explicitly takes weights of ties into account. In formula:

$$
C_{w}=\frac{\sum_{\tau_{\Delta}} w}{\sum_{\tau} w}
$$

with $\tau_{\Delta}$ the number of closed triplets, $\tau$ the number of triplets, and $w$ the weights of ties. $C_{w}$ ranges between 0 and 1 .

The interconnectedness of the interbank market is fairly moderate and seems to follow a slightly increasing trend. The coefficient reaches its maximum in 2008, when the turmoil turns into the financial crisis and remains high during the crisis. The low is 0.51 , which occurs at the beginning of the observation period, before the turmoil starts. The highest peak (0.62) is in the third period of 2008, exactly when the most severe phase of the crisis began. The increase in market uncertainty, therefore, seems to slightly increase market complexity as well as banks' propensity to trade money with closed cohesive groups of partners. The increase in the tendency toward clustering emerges later than the tendency toward reciprocity.

\subsection{Perspectives from actor-level analysis}

The second level of our analysis examines the position of each bank within the interbank network. We also study the relation between network position and pricing policies. This is a relevant investigation in light of empirical findings in the literature on relationship lending. For instance, Hatzopoulos et al. (2013) show that information on volumes lent does not suffice to explain the average interest rates that classes of borrowers pay in e-MID.

The identification of an actor's involvement in network activity is a crucial topic in the literature on social networks. For instance, the detection of actors important for the network is a long-standing issue. These actors are generally defined as "key players" (see Borgatti 2006), and are usually identified via several indices. Centrality measures focus on the structural importance of nodes (see Freeman 1979). Social capital measures assess which actors benefit most from a specific network structure (see Burt 1992; Borgatti et al. 1998). Key-player detection algorithms identify actors that 
contribute to cohesion and resource diffusion or to network disruption and fragmentation (see Borgatti 2006) and are employed when investigating systemic risks and related issues.

The literature on financial markets focuses mainly on centrality measures by computing their distributions (Iori et al. 2008; Iazzetta and Manna 2009b), or by studying the correlation between actor centrality values and actor behaviors (Ozsoylev et al. 2011). Various centrality measures have been adopted for these purposes. For instance, Ozsoylev et al. (2011) use eigenvector centrality, which links actor centrality to the centrality of others to which the actor is connected. ${ }^{10}$ Walden (2013) underlines that other frequently used centrality measures-for example, betweenness and closeness centrality - do not capture the information advantage of the key players. Adamic et al. (2010) use a linear combination of in- and out-degree centrality to identify dominant buyers and sellers.

Our goal is to detect the key players so that we can study the relation between their market activity and their pricing strategies. Hence, we extend the approach of Adamic et al. (2010) in several directions. We detect key players using a complex index that combines different aspects of trading behavior. Intuitively, we would like to measure the importance of a node by looking at its direct ties, which indicate the lending (outgoing) or receiving (incoming) position of a node. In line with Adamic et al. (2010), we assume that both lending and pricing patterns are mostly based on a bank's local position within its neighborhood, that is, mainly on direct interactions rather than on position within the entire network structure.

We identify prominent banks through a measure that weights the amount traded by each bank by the centrality of the bank within the network of transactions. This is a linear transformation of the generalized degree centrality proposed by Opsahl et al. (2010), defined as the product between the number of nodes actor $i$ is connected to (i.e., degree centrality) and the average weight of these nodes (i.e., degree strength). Degree centrality takes into consideration the network activity of each bank. Degree strength accounts for the values of ties, namely, the amount traded by each bank. In doing so, generalized degree centrality summarizes pieces of information that previous papers only interpret separately (see, e.g., Bech and Atalay 2008). Generalized degree centrality has been applied in various settings. It has proven capable of capturing the existence of network hierarchies (Wycislik and Warchal 2012; Kinne 2012). We write our centrality index as:

$$
C_{O}^{w \alpha}(i)=k_{i} \times\left(\frac{s_{i}}{k_{i}}\right)^{\alpha}=k_{i}^{(1-\alpha)} \times s_{i}^{\alpha}
$$

The constant $\alpha$ is a positive tuning parameter that determines the relative importance of the number of ties compared to tie weights (the amount). For $\alpha=0$, the value of the measure equals the degree centrality. So, the measure identifies prominent actors by looking only at their network activity. For $\alpha=1$, the measure equals the node strength. Hence, it accounts for only the amount traded.

\footnotetext{
10 This choice is based on the assumptions that actors earn high profits by trading on the information they obtain through the network and that eigenvector centrality effectively captures access to information.
} 
To investigate the information content of both degree centrality and degree strength, we start by studying the distributions of these indices separately. Then, we provide a synthesis in a key-player measure. Degree centrality counts the number of ties that are incident to a node or, equivalently, the number of nodes adjacent to it (see Freeman 1979). In directed networks, this can be specified as either "in-degree" or "out-degree" centrality, depending on whether incoming or outgoing ties are considered.

In-degree centrality looks at the number of actors that choose $i$ as a counterparty and lend money to it. This is an indicator of a bank's prestige or popularity because it evaluates the $i$ 's market reputation as a trading partner. This is extremely important in the context of our analysis. Since our study focuses on a non-collateralized market, a measure of a bank's reputation in the marketplace conveys relevant information. In-degree centrality is computed as:

$$
k_{+i}=\sum_{j} e_{j i}
$$

where $k+i$ ranges between 0 , if $i$ has no incoming ties, and $(n-1)$.

Out-degree centrality counts the number of nodes to which actor $i$ sends ties, and measures $i$ 's trading activity. This statistic sheds light on a bank's capability to lend cash and to maintain relationships. It takes the form

$$
k_{i+}=\sum_{j} e_{i j}
$$

Examining the shape of the in-degree and out-degree centrality distributions can reveal important patterns. In the literature on social networks, this analysis is usually performed by plotting the empirical distributions against the corresponding power law ones (see Barabasi and Reka 1999). The power law distribution postulates that the probability $P(k)$ that a node interacts with $k$ other nodes decays following $P(k) \propto k^{-\gamma}$ with an exponent $\gamma$ between 2.1 and 4 . The distribution shape introduces the hypothesis that the networks are built through a preferential mechanism, where new actors have a higher probability of connecting to more popular actors than to other agents. This feature leads to "the richer-get-richer" phenomenon, where highly connected nodes (large $k$ ) have a large chance of occurring. ${ }^{11}$

Figures 3 and 4 plot the distributions for in-degree and out-degree centrality, respectively. Consistent with studies based on higher frequency data (e.g., see Iori et al. 2008), our findings show that both the in- and out-degree distributions are heavy tailed, although they do not follow a proper power law. This shape suggests the presence of a high degree of heterogeneity across banks in their trading behavior. It also justifies the choice of accounting for the network activity of each bank when studying its behavior. Figures 3 and 4 also indicate that there are several banks that exchange cash with just a few counterparties, whereas other banks tend to deal with a wider pool of institutions. The in-degree distribution is especially right tailed, suggesting that some banks borrowed from a range of 103-107 banks at most until 2007, 89-99

11 Ozsoylev and Walden (2009) suggest that this topological property holds for complex networks. 
(a) 2006, quarter=I

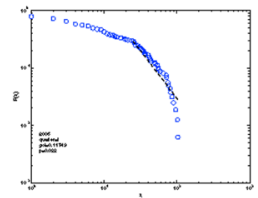

(e) 2007 , quarter $=\mathrm{I}$

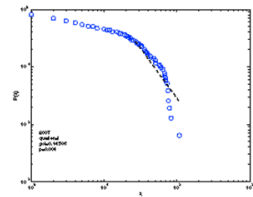

(i) 2008, quarter $=\mathrm{I}$

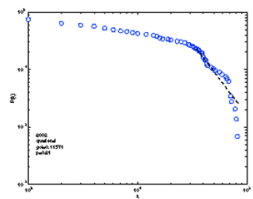

(m) 2009, quarter=I

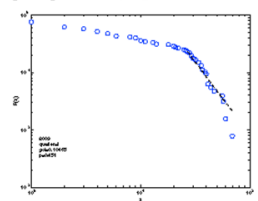

(b) 2006 , quarter=II

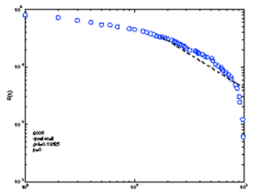

(f) 2007 , quarter=II

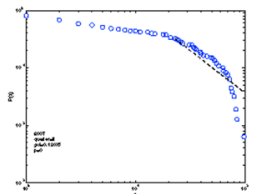

(j) 2008 , quarter=II

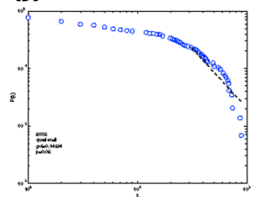

(n) 2009, quarter $=$ II

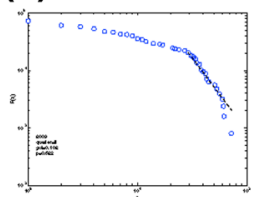

(c) 2006, quarter=III

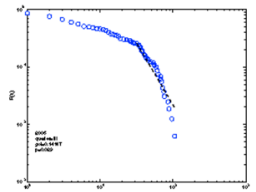

(g) 2007, quarter=III

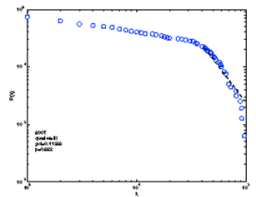

(k) 2008, quarter $=$ III

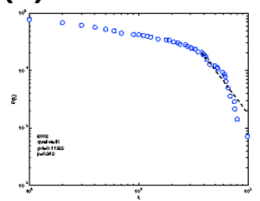

(o) 2009, quarter=III

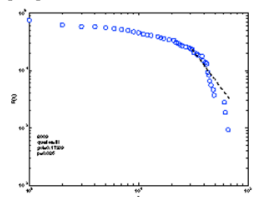

(d) 2006, quarter $=\mathrm{IV}$

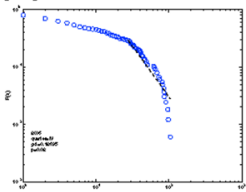

(h) 2007 , quarter $=\mathrm{IV}$

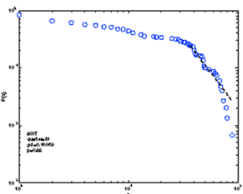

(I) 2008 , quarter $=\mathrm{IV}$

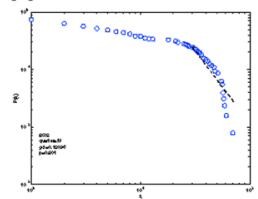

(p) 2009, quarter $=\mathrm{IV}$

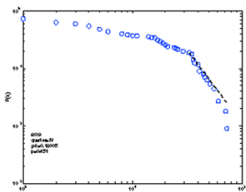

Fig. 3 In-degree probability distribution with power law fitting. Legend: on the horizontal axis there are the in-degree (panels $\mathbf{a}-\mathbf{d}$ ) values and on the vertical axis the complement of the cumulative distribution function $P(X)=P(X \geq x)$. The points represent the observed values of the cumulative density functions and the dashed line the corresponding power law. The goodness of fit between the data and the power law is calculated using the method described in Clauset et al. (2009) and based on a Kolmogorov-Smirnov statistic. Since the resulting $p$ value is smaller than 0.1 the power law is not a plausible hypothesis for the data

banks in 2008, and 66-73 in 2009. While the shapes of the in- and out-degree distributions remain almost the same over time, a deeper investigation of the descriptive statistics indicates that the absolute values have decreased fairly constantly, in line with the reduction in market size. The average number of counterparties is 19 in all quarters of 2006 and 18 in 2007, then falls to 14 at the end of 2008 and to 14 in 2009.

Building on Bech and Atalay (2008), we explore the amount traded by each bank, that is, its financial strength. The key question in this context is whether the traded volumes are controlled by a small number of banks. ${ }^{12}$ Hence, we measure node strength (see Barrat et al. 2004) as the sum of $i$ 's incoming or outgoing tie weights $w_{i j}$ :

$$
s_{+i}=\sum_{j} w_{j i}
$$

\footnotetext{
12 Note that the high values of market concentration support this proposition.
} 
(a) 2006 , quarter $=\mathrm{I}$

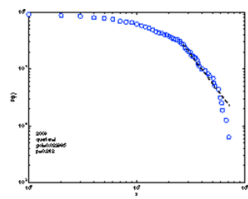

(e) 2007 , quarter $=\mathrm{I}$

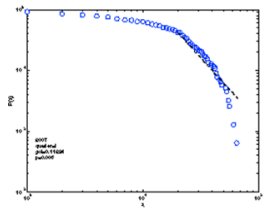

(i) 2008 , quarter $=\mathrm{I}$

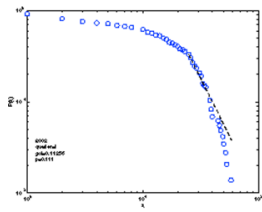

(m) 2009, quarter=I

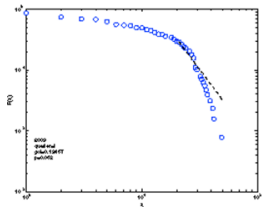

(b) 2006 , quarter $=$ II

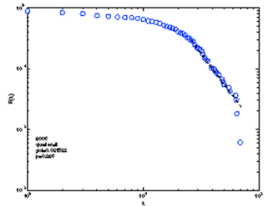

(f) 2007 , quarter $=$ II

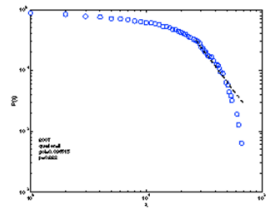

(j) 2008, quarter=II

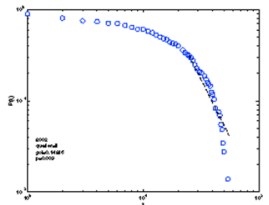

(n) 2009 , quarter $=$ II

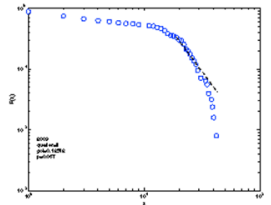

(c) 2006 , quarter $=$ III

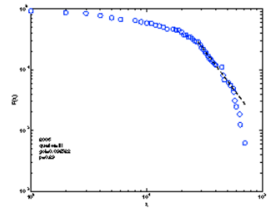

(g) 2007 , quarter $=$ III

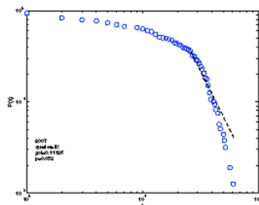

(k) 2008 , quarter $=$ III

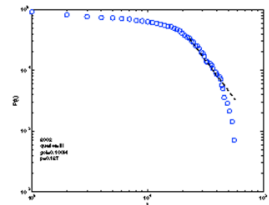

(o) 2009, quarter=III

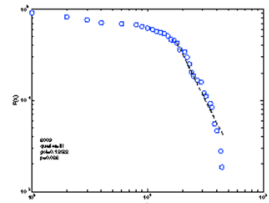

(d) 2006 , quarter $=\mathrm{IV}$

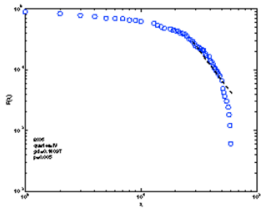

(h) 2007 , quarter $=\mathrm{IV}$

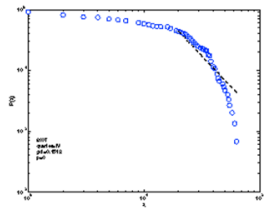

(I) 2008 , quarter $=\mathrm{IV}$

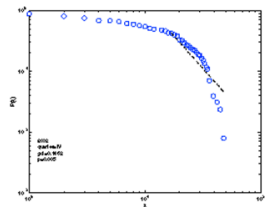

(p) 2009, quarter $=\mathrm{IV}$

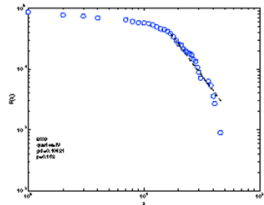

Fig. 4 Out-degree probability distribution with power law fitting. Legend: on the horizontal axis there are the out-degree (panels $\mathbf{a}-\mathbf{d}$ ) values and on the vertical axis the complement of the cumulative distribution function $P(X)=P(X \geq x)$. The points represent the observed values of the cumulative density functions and the dashed line the corresponding power law. The goodness of fit between the data and the power law is calculated using the method described in Clauset et al. (2009) and based on a Kolmogorov-Smirnov statistic. Since the resulting $p$ value is smaller than 0.1 the power law is not a plausible hypothesis for the data

for incoming ties and

$$
s_{i+}=\sum_{i} w_{i j}
$$

for outgoing ties. For reasons of parsimony, the in- and out-strength distributions are not displayed here. However, we note that they resemble the related dichotomous degree version. They are both skewed and heavy tailed, suggesting that few banks borrow-or lend, on the other side of the market-large amounts of cash.

In Tables 5, 6, 7 and 8, we report Pearson's correlation coefficients between node degree and strength for each quarter. ${ }^{13}$ These measures are only partially proportional to one another. Specifically, the values vary between 0.39 (in the fourth quarter of

\footnotetext{
13 The correlations are computed for five values of $\alpha$, within a range of $\alpha=0$ and $\alpha=1$.
} 
Table 5 Pearson's correlation coefficients between pairs of generalized degree centrality indices for year $2006(0 \leq \alpha \leq 1)$

\begin{tabular}{|c|c|c|c|c|c|c|c|c|c|c|}
\hline \multicolumn{6}{|c|}{ Outgoing ties } & \multicolumn{5}{|c|}{ Incoming ties } \\
\hline$\alpha$ & 0 & 0.25 & 0.50 & 0.75 & 1.00 & 0 & 0.25 & 0.50 & 0.75 & 1.00 \\
\hline & \multicolumn{5}{|c|}{ Quarter I } & \multicolumn{5}{|c|}{ Quarter I } \\
\hline 0 & \multicolumn{5}{|l|}{1.000} & \multicolumn{5}{|l|}{1.000} \\
\hline 0.25 & 0.951 & 1.000 & & & & 0.973 & 1.000 & & & \\
\hline 0.50 & 0.859 & 0.974 & 1.000 & & & 0.920 & 0.985 & 1.000 & & \\
\hline 0.75 & 0.765 & 0.920 & 0.984 & 1.000 & & 0.861 & 0.952 & 0.990 & 1.000 & \\
\hline \multirow[t]{2}{*}{1.00} & 0.675 & 0.853 & 0.945 & 0.988 & 1.000 & 0.800 & 0.909 & 0.965 & 0.992 & 1.000 \\
\hline & \multicolumn{5}{|c|}{ Quarter II } & \multicolumn{5}{|c|}{ Quarter II } \\
\hline 0 & \multicolumn{5}{|l|}{1.000} & \multicolumn{5}{|l|}{1.000} \\
\hline 0.25 & 0.952 & 1.000 & & & & 0.974 & 1.000 & & & \\
\hline 0.50 & 0.853 & 0.970 & 1.000 & & & 0.922 & 0.985 & 1.000 & & \\
\hline 0.75 & 0.746 & 0.906 & 0.981 & 1.000 & & 0.864 & 0.953 & 0.990 & 1.000 & \\
\hline \multirow[t]{2}{*}{1.00} & 0.648 & 0.833 & 0.938 & 0.987 & 1.000 & 0.806 & 0.912 & 0.967 & 0.993 & 1.000 \\
\hline & \multicolumn{5}{|c|}{ Quarter III } & \multicolumn{5}{|c|}{ Quarter III } \\
\hline 0 & \multicolumn{5}{|l|}{1.000} & \multicolumn{5}{|l|}{1.000} \\
\hline 0.25 & 0.950 & 1.000 & & & & 0.964 & 1.000 & & & \\
\hline 0.50 & 0.844 & 0.967 & 1.000 & & & 0.888 & 0.977 & 1.000 & & \\
\hline 0.75 & 0.720 & 0.890 & 0.976 & 1.000 & & 0.804 & 0.929 & 0.986 & 1.000 & \\
\hline \multirow[t]{2}{*}{1.00} & 0.600 & 0.794 & 0.917 & 0.981 & 1.000 & 0.727 & 0.874 & 0.955 & 0.991 & 1.000 \\
\hline & \multicolumn{5}{|c|}{ Quarter IV } & \multicolumn{5}{|c|}{ Quarter IV } \\
\hline 0 & 1.000 & & & & & 1.000 & & & & \\
\hline 0.25 & 0.950 & 1.000 & & & & 0.964 & 1.000 & & & \\
\hline 0.50 & 0.844 & 0.967 & 1.000 & & & 0.888 & 0.977 & 1.000 & & \\
\hline 0.75 & 0.721 & 0.890 & 0.976 & 1.000 & & 0.804 & 0.929 & 0.986 & 1.000 & \\
\hline 1.00 & 0.600 & 0.794 & 0.917 & 0.981 & 1.000 & 0.727 & 0.874 & 0.955 & 0.991 & 1.000 \\
\hline
\end{tabular}

The correlation coefficients are all significant at 0.05 level

2008) and 0.69 (in the second quarter of 2007) for outgoing ties, and between 0.70 (in the third quarter of 2009) and 0.97 (in the second quarter of 2007) for incoming ties. Hence, a separate analysis of the two measures - especially for outgoing ties-may provide incomplete information on node prominence. Using a composite indicator such as the generalized degree centrality index appears to be a reasonable empirical strategy for detecting key players.

\section{Our approach for detecting key players}

We define key players with a linear transformation of the generalized degree centrality index. This approach accounts for node degree and node strength and for outgoing and incoming ties. This definition allows testing the proposition that actors in the interbank market play different roles, that is, some banks are net lenders while others are net 
Table 6 Pearson's correlation coefficients between pairs of generalized degree centrality indices for year $2007(0 \leq \alpha \leq 1)$

\begin{tabular}{|c|c|c|c|c|c|c|c|c|c|c|}
\hline \multicolumn{6}{|c|}{ Outgoing ties } & \multicolumn{5}{|c|}{ Incoming ties } \\
\hline$\alpha$ & 0 & 0.25 & 0.50 & 0.75 & 1.00 & 0 & 0.25 & 0.50 & 0.75 & 1.00 \\
\hline & \multicolumn{5}{|c|}{ Quarter I } & \multicolumn{5}{|c|}{ Quarter I } \\
\hline 0 & \multicolumn{5}{|l|}{1.000} & \multicolumn{5}{|l|}{1.000} \\
\hline 0.25 & 0.946 & 1.000 & & & & 0.975 & 1.000 & & & \\
\hline 0.50 & 0.840 & 0.969 & 1.000 & & & 0.919 & 0.983 & 1.000 & & \\
\hline 0.75 & 0.732 & 0.906 & 0.982 & 1.000 & & 0.848 & 0.941 & 0.987 & 1.000 & \\
\hline \multirow[t]{2}{*}{1.00} & 0.638 & 0.836 & 0.943 & 0.988 & 1.000 & 0.773 & 0.885 & 0.953 & 0.989 & 1.000 \\
\hline & \multicolumn{5}{|c|}{ Quarter II } & \multicolumn{5}{|c|}{ Quarter II } \\
\hline 0 & \multicolumn{5}{|l|}{1.000} & \multicolumn{5}{|l|}{1.000} \\
\hline 0.25 & 0.955 & 1.000 & & & & 0.975 & 1.000 & & & \\
\hline 0.50 & 0.865 & 0.974 & 1.000 & & & 0.920 & 0.984 & 1.000 & & \\
\hline 0.75 & 0.771 & 0.919 & 0.984 & 1.000 & & 0.856 & 0.947 & 0.989 & 1.000 & \\
\hline \multirow[t]{2}{*}{1.00} & 0.689 & 0.860 & 0.951 & 0.990 & 1.000 & 0.971 & 0.901 & 0.963 & 0.992 & 1.000 \\
\hline & \multicolumn{5}{|c|}{ Quarter III } & \multicolumn{5}{|c|}{ Quarter III } \\
\hline 0 & \multicolumn{5}{|l|}{1.000} & \multicolumn{5}{|l|}{1.000} \\
\hline 0.25 & 0.946 & 1.000 & & & & 0.979 & 1.000 & & & \\
\hline 0.50 & 0.837 & 0.968 & 1.000 & & & 0.928 & 0.984 & 1.000 & & \\
\hline 0.75 & 0.724 & 0.900 & 0.980 & 1.000 & & 0.862 & 0.945 & 0.988 & 1.000 & \\
\hline \multirow[t]{2}{*}{1.00} & 0.622 & 0.824 & 0.936 & 0.987 & 1.000 & 0.788 & 0.891 & 0.955 & 0.990 & 1.000 \\
\hline & \multicolumn{5}{|c|}{ Quarter IV } & \multicolumn{5}{|c|}{ Quarter IV } \\
\hline 0 & 1.000 & & & & & 1.000 & & & & \\
\hline 0.25 & 0.953 & 1.000 & & & & 0.975 & 1.000 & & & \\
\hline 0.50 & 0.861 & 0.973 & 1.000 & & & 0.923 & 0.985 & 1.000 & & \\
\hline 0.75 & 0.754 & 0.909 & 0.979 & 1.000 & & 0.862 & 0.950 & 0.990 & 1.000 & \\
\hline 1.00 & 0.604 & 0.778 & 0.882 & 0.955 & 1.000 & 0.800 & 0.906 & 0.964 & 0.992 & 1.000 \\
\hline
\end{tabular}

The correlation coefficients are all significant at 0.05 level

borrowers. In particular, we consider the idea that some of the institutions control the cash flow exchanged in the market by lending (or borrowing) large amounts of money to (from) many counterparties. They represent large net lenders (borrowers) to (from) the market. In other words, the role of a big lender involves a combination of lending large volumes to many banks, and borrowing small volumes from just a few others. A big borrower is one that receives cash from many counterparties, while lending to a few.

In statistical terms, the key players are identified by a high absolute value of the difference between the generalized out- and in-degree centrality, denoted by $C_{O-I}^{w \alpha}(i)$. If this difference is positive, the key player is a net lender; otherwise, it is a net borrower. From an economic point of view, understanding the role of key players requires introducing hypotheses not yet considered in the literature. A large share of market volume controlled by key players suggests that available funds are not 
Table 7 Pearson's correlation coefficients between pairs of generalized degree centrality indices for year $2008(0 \leq \alpha \leq 1)$

\begin{tabular}{|c|c|c|c|c|c|c|c|c|c|c|}
\hline \multicolumn{6}{|c|}{ Outgoing ties } & \multicolumn{5}{|c|}{ Incoming ties } \\
\hline$\alpha$ & 0 & 0.25 & 0.50 & 0.75 & 1.00 & 0 & 0.25 & 0.50 & 0.75 & 1.00 \\
\hline & \multicolumn{5}{|c|}{ Quarter I } & \multicolumn{5}{|c|}{ Quarter I } \\
\hline 0 & \multicolumn{5}{|l|}{1.000} & \multicolumn{5}{|l|}{1.000} \\
\hline 0.25 & 0.953 & 1.000 & & & & 0.975 & 1.000 & & & \\
\hline 0.50 & 0.861 & 0.973 & 1.000 & & & 0.923 & 0.985 & 1.000 & & \\
\hline 0.75 & 0.754 & 0.909 & 0.979 & 1.000 & & 0.863 & 0.950 & 0.990 & 1.000 & \\
\hline \multirow[t]{2}{*}{1.00} & 0.604 & 0.778 & 0.882 & 0.955 & 1.000 & 0.800 & 0.906 & 0.964 & 0.992 & 1.000 \\
\hline & \multicolumn{5}{|c|}{ Quarter II } & \multicolumn{5}{|c|}{ Quarter II } \\
\hline 0 & \multicolumn{5}{|l|}{1.000} & \multicolumn{5}{|l|}{1.000} \\
\hline 0.25 & 0.953 & 1.000 & & & & 0.974 & 1.000 & & & \\
\hline 0.50 & 0.856 & 0.971 & 1.000 & & & 0.924 & 0.986 & 1.000 & & \\
\hline 0.75 & 0.749 & 0.908 & 0.981 & 1.000 & & 0.868 & 0.954 & 0.991 & 1.000 & \\
\hline \multirow[t]{2}{*}{1.00} & 0.649 & 0.835 & 0.938 & 0.987 & 1.000 & 0.809 & 0.912 & 0.966 & 0.992 & 1.000 \\
\hline & \multicolumn{5}{|c|}{ Quarter III } & \multicolumn{5}{|c|}{ Quarter III } \\
\hline 0 & \multicolumn{5}{|l|}{1.000} & \multicolumn{5}{|l|}{1.000} \\
\hline 0.25 & 0.951 & 1.000 & & & & 0.975 & 1.000 & & & \\
\hline 0.50 & 0.849 & 0.970 & 1.000 & & & 0.922 & 0.984 & 1.000 & & \\
\hline 0.75 & 0.740 & 0.906 & 0.981 & 1.000 & & 0.861 & 0.949 & 0.989 & 1.000 & \\
\hline \multirow[t]{2}{*}{1.00} & 0.643 & 0.834 & 0.940 & 0.988 & 1.000 & 0.799 & 0.905 & 0.964 & 0.992 & 1.000 \\
\hline & \multicolumn{5}{|c|}{ Quarter IV } & \multicolumn{5}{|c|}{ Quarter IV } \\
\hline 0 & \multicolumn{5}{|l|}{1.000} & \multicolumn{5}{|l|}{1.000} \\
\hline 0.25 & 0.954 & 1.000 & & & & 0.975 & 1.000 & & & \\
\hline 0.50 & 0.819 & 0.950 & 1.000 & & & 0.910 & 0.979 & 1.000 & & \\
\hline 0.75 & 0.611 & 0.798 & 0.943 & 1.000 & & 0.821 & 0.922 & 0.981 & 1.000 & \\
\hline 1.00 & 0.389 & 0.591 & 0.795 & 0.949 & 1.000 & 0.718 & 0.843 & 0.932 & 0.984 & 1.000 \\
\hline
\end{tabular}

The correlation coefficients are all significant at 0.05 level

distributed evenly across market participants. The presence of non-atomistic actors raises the question of whether e-MID is characterized by perfect competition.

Since there is no information as to the weight to be assigned to node degree and strength, a meaningful value for the parameter $\alpha$ cannot be set a priori. Following Opsahl et al. (2010), we experiment with five different values, namely, 0, 0.25, 0.50, 0.75 , and 1 . Using only the volumes traded would completely ignore the network structure and imply $\alpha=1$. By contrast, considering only the network position would require setting $\alpha=0$. Hence, we use these two extreme values as a benchmark. Using the three central values of $\alpha-0.25,0.50$, and $0.75-$ assigns an increasing role to information in traded volumes, while providing understanding of how network degree centrality influences banks' pricing strategies.

The Pearson's correlation coefficients computed between pairs of generalized degree centrality distributions suggest that the value $\alpha=0.5$ is the most suitable for our exploratory investigation. For both outgoing and incoming ties, this value gen- 
Table 8 Pearson's correlation coefficients between pairs of generalized degree centrality indices for year $2009(0 \leq \alpha \leq 1)$

\begin{tabular}{|c|c|c|c|c|c|c|c|c|c|c|}
\hline \multicolumn{6}{|c|}{ Outgoing ties } & \multicolumn{5}{|c|}{ Incoming ties } \\
\hline$\alpha$ & 0 & 0.25 & 0.50 & 0.75 & 1.00 & 0 & 0.25 & 0.50 & 0.75 & 1.00 \\
\hline & \multicolumn{5}{|c|}{ Quarter I } & \multicolumn{5}{|c|}{ Quarter I } \\
\hline 0 & \multicolumn{5}{|l|}{1.000} & \multicolumn{5}{|l|}{1.000} \\
\hline 0.25 & 0.963 & 1.000 & & & & 0.970 & 1.000 & & & \\
\hline 0.50 & 0.876 & 0.972 & 1.000 & & & 0.904 & 0.980 & 1.000 & & \\
\hline 0.75 & 0.769 & 0.907 & 0.980 & 1.000 & & 0.826 & 0.935 & 0.986 & 1.000 & \\
\hline \multirow[t]{2}{*}{1.00} & 0.663 & 0.828 & 0.934 & 0.986 & 1.000 & 0.749 & 0.878 & 0.953 & 0.990 & 1.000 \\
\hline & \multicolumn{5}{|c|}{ Quarter II } & \multicolumn{5}{|c|}{ Quarter II } \\
\hline 0 & \multicolumn{5}{|l|}{1.000} & \multicolumn{5}{|l|}{1.000} \\
\hline 0.25 & 0.963 & 1.000 & & & & 0.970 & 1.000 & & & \\
\hline 0.50 & 0.876 & 0.972 & 1.000 & & & 0.904 & 0.980 & 1.000 & & \\
\hline 0.75 & 0.769 & 0.907 & 0.980 & 1.000 & & 0.826 & 0.935 & 0.986 & 1.000 & \\
\hline \multirow[t]{2}{*}{1.00} & 0.663 & 0.828 & 0.934 & 0.986 & 1.000 & 0.749 & 0.878 & 0.953 & 0.990 & 1.000 \\
\hline & \multicolumn{5}{|c|}{ Quarter III } & \multicolumn{5}{|c|}{ Quarter III } \\
\hline 0 & \multicolumn{5}{|l|}{1.000} & \multicolumn{5}{|l|}{1.000} \\
\hline 0.25 & 0.949 & 1.000 & & & & 0.971 & 1.000 & & & \\
\hline 0.50 & 0.841 & 0.967 & 1.000 & & & 0.899 & 0.976 & 1.000 & & \\
\hline 0.75 & 0.724 & 0.899 & 0.980 & 1.000 & & 0.803 & 0.917 & 0.981 & 1.000 & \\
\hline \multirow[t]{2}{*}{1.00} & 0.617 & 0.822 & 0.936 & 0.987 & 1.000 & 0.702 & 0.840 & 0.935 & 0.986 & 1.000 \\
\hline & \multicolumn{5}{|c|}{ Quarter IV } & \multicolumn{5}{|c|}{ Quarter IV } \\
\hline 0 & 1.000 & & & & & 1.000 & & & & \\
\hline 0.25 & 0.962 & 1.000 & & & & 0.969 & 1.000 & & & \\
\hline 0.50 & 0.870 & 0.971 & 1.000 & & & 0.900 & 0.979 & 1.000 & & \\
\hline 0.75 & 0.756 & 0.902 & 0.978 & 1.000 & & 0.822 & 0.934 & 0.987 & 1.000 & \\
\hline 1.00 & 0.639 & 0.813 & 0.925 & 0.983 & 1.000 & 0.749 & 0.882 & 0.957 & 0.991 & 1.000 \\
\hline
\end{tabular}

The correlation coefficients are all significant at 0.05 level

erates correlation coefficients that are higher than those of alternative $\alpha$. It summarizes adequately both the information on volumes traded and the number of counterparties. Also, it assigns equal importance to them, thus providing the most conservative list of "key players".

Figure 5 plots the $C_{O-I}^{w \alpha}(i)$ distributions, $\alpha=0.5$. For all the sample period, the distribution exhibits a similar shape, which is fairly symmetric around 0 , i.e., the neutral position. The first part of the distribution is flat, then increases steadily, following a linear function, and finally very sharply in the tails. About $35-40 \%$ of the actors fall within a very small interval around 0 . Therefore, they do not have a definite role nor market power, but lend/borrow around the same amount of money to/from a similar number of counterparties. Each of these banks has a market share smaller than $0.2 \%$.

The left and right tails of the distributions depicted in Fig. 5 identify banks that act mainly as either only lenders, or only borrower. Depending on which value of $C_{O-I}^{w \alpha}(i)$ we use to identify the tails, we observe that institutions located in this part of 
(a) 2006, quarter=I

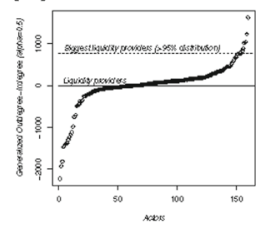

(e) 2007, quarter $=\mathrm{I}$

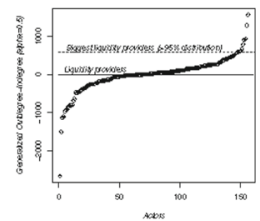

(i) 2008, quarter $=\mathrm{I}$

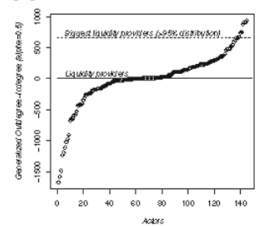

(m) 2009, quarter=I

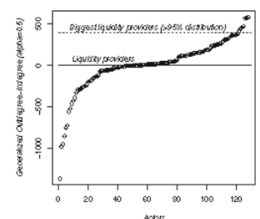

(b) 2006 , quarter $=I I$

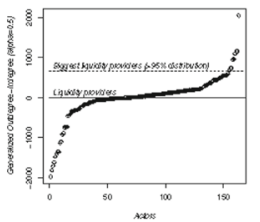

(f) 2007 , quarter $=\mathrm{II}$

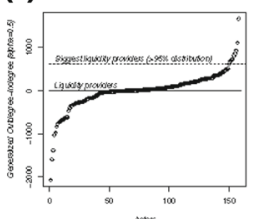

(j) 2008, quarter $=$ II

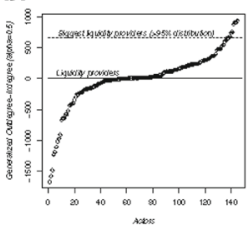

(n) 2009, quarter $=$ II

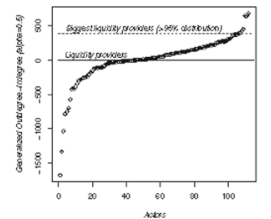

(c) 2006, quarter $=$ III

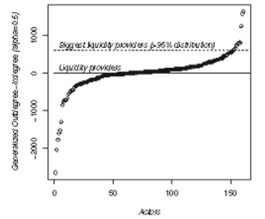

(g) 2007 , quarter $=$ III

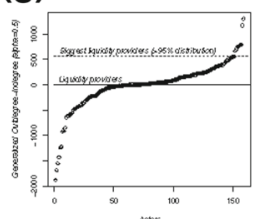

(k) 2008, quarter $=$ III

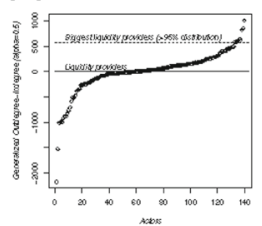

(o) 2009, quarter=III

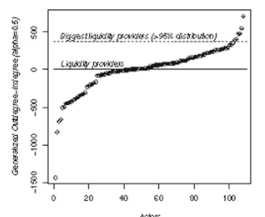

(d) 2006, quarter $=\mathrm{IV}$

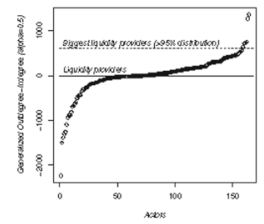

(h) 2007 , quarter $=\mathrm{IV}$

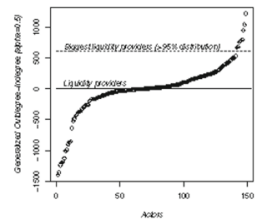

(I) 2008, quarter $=\mathrm{TV}$

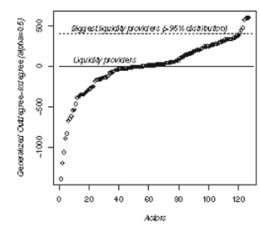

(p) 2009, quarter $=\mathrm{NV}$

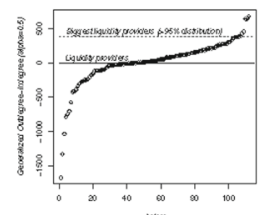

Fig. 5 Distributions of net cash providers. Legend: the graphs report the actors on the horizontal axis, and $C_{O-I}^{w \alpha}(i)$ on the vertical axis

the distribution account for around $35-40 \%$ of volumes traded in the market. In other words, the largest share of cash in e-MID is traded by a small number of banks. Both the demand and the supply side of the market are characterized by banks that play a clear role either as lenders, or as borrowers.

The increase in the values of $C_{O-I}^{w \alpha}(i)$ and also in the market shares is particularly sharp after the 95 th percentile, and before the 5th percentile. To investigate the link between being a key player and enjoying market power, we focus our attention on the tails of the $C_{O-I}^{w \alpha}(i)$ distribution. Hence, we set the threshold $t_{1}=95$ th percentile and define as large cash providers the banks with $C_{O-I}^{w \alpha}(i) \geq t_{1}$. Then, we set $t_{2}=5$ th percentile and consider as large cash borrowers the institutions with a value of $C_{O-I}^{w \alpha}(i) \leq$ $t_{2}$. According to our definition, we consider both types of banks as key players.

\section{What role for big lenders and big borrowers?}

Identifying which nodes play a key role in a network is a difficult task. This is especially the case in financial markets where the opportunistic behavior of market players is 
Table 9 Descriptive statistics for the big lenders for 2006-2007

\begin{tabular}{|c|c|c|c|c|c|c|c|c|c|}
\hline 2006 I & Market & GR0006 & IT0185 & IT0187 & IT0257 & IT0258 & IT0259 & IT0269 & IT0278 \\
\hline Rate & 2.398 & 2.420 & 2.433 & 2.408 & 2.360 & 2.406 & 2.418 & 2.418 & 2.396 \\
\hline Std dev & & 0.119 & 0.111 & 0.116 & 0.130 & 0.123 & 0.129 & 0.124 & 0.111 \\
\hline Amount & 579586.34 & 19193.9 & 17840.05 & 18110.13 & 31921.32 & 28070.16 & 16401.54 & 47313.8 & 18082.8 \\
\hline Trades & & 378 & 428 & 1169 & 859 & 1008 & 837 & 1375 & 870 \\
\hline Perc & & 3.312 & 3.078 & 3.125 & 5.508 & 4.843 & 2.830 & 8.163 & 3.120 \\
\hline 2006 II & Market & IT0185 & IT0187 & IT0258 & IT0259 & IT0261 & IT0265 & IT0269 & IT0279 \\
\hline Rate & 2.628 & 2.670 & 2.627 & 2.619 & 2.653 & 2.621 & 2.633 & 2.617 & 2.668 \\
\hline Std dev & & 0.111 & 0.108 & 0.117 & 0.138 & 0.109 & 0.092 & 0.121 & 0.153 \\
\hline Amount & 594392.460 & 18831.7 & 12824.1 & 22543.85 & 16685.08 & 26772.28 & 31562.68 & 67186.09 & 26383.6 \\
\hline Trades & & 365 & 828 & 822 & 658 & 575 & 334 & 1657 & 989 \\
\hline Perc & & 3.168 & 2.158 & 3.793 & 2.807 & 4.504 & 5.310 & 11.303 & 4.439 \\
\hline 2006 III & Market & IT0193 & IT0258 & IT0259 & IT0261 & IT0263 & IT0265 & IT0269 & IT0279 \\
\hline Rate & 2.927 & 2.941 & 2.887 & 2.928 & 2.919 & 2.923 & 2.916 & 2.924 & 2.916 \\
\hline Std dev & & 0.135 & 0.118 & 0.134 & 0.129 & 0.141 & 0.140 & 0.132 & 0.137 \\
\hline Amount & 557422.51 & 10430.79 & 20232.34 & 26046.97 & 18495.55 & 14135 & 21187.62 & 43444.93 & 55409.01 \\
\hline Trades & & 789 & 790 & 839 & 415 & 348 & 255 & 1280 & 1533 \\
\hline Perc & & 1.871 & 3.630 & 4.673 & 3.318 & 2.536 & 3.801 & 7.794 & 9.940 \\
\hline 2006 IV & Market & GR0006 & IT0173 & IT0187 & IT0193 & IT0242 & IT0265 & IT0269 & IT0279 \\
\hline Rate & 3.363 & 3.352 & 3.359 & 3.382 & 3.359 & 3.403 & 3.431 & 3.355 & 3.354 \\
\hline Std dev & & 0.151 & 0.148 & 0.144 & 0.140 & 0.164 & 0.181 & 0.151 & 0.146 \\
\hline Amount & 496636.84 & 14159.7 & 11520 & 12451.2 & 9023.71 & 7264.4 & 14336 & 40279.56 & 36338.89 \\
\hline Trades & & 266 & 522 & 810 & 812 & 494 & 240 & 1085 & 1311 \\
\hline Perc & & 2.851 & 2.320 & 2.507 & 1.817 & 1.463 & 2.887 & 8.110 & 7.317 \\
\hline 2007 I & Market & IT0187 & IT0193 & IT0198 & IT0257 & IT0261 & IT0269 & IT0279 & \\
\hline Rate & 3.601 & 3.614 & 3.604 & 3.605 & 3.619 & 3.642 & 3.602 & 3.583 & \\
\hline Std dev & & 0.129 & 0.182 & 0.156 & 0.132 & 0.128 & 0.156 & 0.137 & \\
\hline Amount & 489614.46 & 15263.6 & 8510.07 & 10197.8 & 43397.45 & 22892.45 & 27298.62 & 23717.37 & \\
\hline Trades & 21083 & 1073 & 830 & 559 & 1267 & 407 & 928 & 1083 & \\
\hline Perc & & 3.117 & 1.738 & 2.083 & 8.864 & 4.676 & 5.576 & 4.844 & \\
\hline 2007 II & Market & IT0185 & IT0187 & IT0208 & IT0257 & IT0261 & IT0269 & IT0279 & \\
\hline Rate & 3.849 & 3.876 & 3.858 & 3.853 & 3.858 & 3.877 & 3.824 & 3.807 & \\
\hline Std dev & & 0.099 & 0.149 & 0.161 & 0.155 & 0.165 & 0.176 & 0.171 & \\
\hline Amount & 459956.79 & 18727.5 & 16853.26 & 10922.8 & 43270.31 & 23833.94 & 23080 & 13118.2 & \\
\hline Trades & 20047 & 428 & 1091 & 646 & 1221 & 538 & 807 & 612 & \\
\hline Perc & & 4.072 & 3.664 & 2.375 & 9.407 & 5.182 & 5.018 & 2.852 & \\
\hline
\end{tabular}


Table 9 continued

\begin{tabular}{llllllllll}
\hline 2007 III & Market & IT0187 & IT0193 & IT0208 & IT0224 & IT0255 & IT0261 & IT0269 & IT0279 \\
\hline Rate & 4.077 & 4.107 & 4.107 & 4.087 & 4.087 & 4.049 & 4.073 & 4.060 & 4.014 \\
Std dev & & 0.190 & 0.226 & 0.264 & 0.212 & 0.161 & 0.160 & 0.223 & 0.243 \\
Amount & 521465.09 & 16585.8 & 11237.1 & 10619.8 & 14523.97 & 13577.26 & 41724.16 & 29354 & 15553.4 \\
Trades & 23,738 & 1135 & 971 & 810 & 544 & 399 & 1114 & 1223 & 763 \\
Perc & & 3.181 & 2.155 & 2.037 & 2.785 & 2.604 & 8.001 & 5.629 & 2.983 \\
\hline 2007 IV & Market & IT0187 & IT0193 & IT0224 & IT0255 & IT0261 & IT0269 & IT0279 & \\
\hline Rate & 3.943 & 3.970 & 3.963 & 3.938 & 3.950 & 3.982 & 3.923 & 3.898 & \\
Std dev & & 0.139 & 0.154 & 0.198 & 0.166 & 0.151 & 0.183 & 0.165 & \\
Amount & 437707.9 & 12469.1 & 11737.64 & 14362.63 & 15140.6 & 25628.34 & 26735.6 & 25187.11 \\
Trades & 21,579 & 1021 & 1112 & 716 & 404 & 877 & 1047 & 1080 & \\
Perc & & 2.849 & 2.682 & 3.281 & 3.459 & 5.855 & 6.108 & 5.754 & \\
\hline
\end{tabular}

Rate mean rate, Std dev standard deviation of interest rate, Amount total amount lent, Perc market share of total amount traded, Trades number of trades

hard to detect. The descriptive measures proposed in the previous section point to the presence of asymmetries in the interbank market. However, the opacity of the information available does not allow a structural interpretation of these patterns.

In this section, we discuss key-player characteristics in detail. We start by focusing on the 95th percentile of the distribution in Fig. 5. This provides information on the "big lenders", namely, the banks that lend a great deal of cash while borrowing little. We then examine the 5 th percentile of the distribution in Fig. 5. This tail identifies the "big borrowers", which are the key drivers of the net demand for cash.

The empirical distributions reported in Fig. 5 are characterized by an invariant right tail for 2006 and 2007. A similar picture emerges between 2008 and 2009. The nodes change between 2007 and 2008, suggesting that an important change took place in 2007. In general, the eruption of financial market turmoil the Euro area in August 2007 appears to have modified the prevailing organization of the market. ${ }^{14}$

Who are the key players? To shed light on the microstructure of exchanges, we report some descriptive statistics on the lending activities of the big lenders in Tables 9 and 10. To avoid approximation errors, in this section we report statistics from the original tick-by-tick dataset. There are several dimensions of interest. The first one concerns the market share covered by the big players. The descriptive statistics in Tables 9 and 10 show that these actors are indeed "big". For instance, in each quarter of 2006 and 2007, the percentage of cash supplied by these banks to the market was never less than $29 \%$ of the total volume. Tables 11 and 12 report some descriptive statistics on the borrowing activities of the big borrowers. The tables reveal that the

\footnotetext{
14 Tensions in segments of the U.S.-dollar-denominated money markets reached their highest point on August 9, 2007. To stabilize market conditions, the ECB started a series of open-market operations supplying Euro-denominated cash.
} 
Table 10 Descriptive statistics for the big lenders for 2008-2009

\begin{tabular}{|c|c|c|c|c|c|c|c|c|}
\hline $2008 \mathrm{I}$ & Market & IT0193 & IT0224 & IT0255 & IT0264 & IT0269 & IT0279 & \\
\hline Rate & 4.04 & 4.042 & 4.039 & 4.030 & 4.041 & 4.036 & 4.002 & \\
\hline Std dev & & 0.097 & 0.087 & 0.083 & 0.088 & 0.109 & 0.110 & \\
\hline Amount & 405109.34 & 10300 & 16614.19 & 21132.39 & 21185 & 14031.21 & 25890.26 & \\
\hline Trades & & 1012 & 729 & 517 & 332 & 612 & 992 & \\
\hline Perc & & 2.543 & 4.101 & 5.216 & 5.229 & 3.464 & 6.391 & \\
\hline 2008 II & Market & IT0193 & IT0198 & IT0224 & IT0255 & IT0261 & IT0269 & IT0279 \\
\hline Rate & 3.971 & 3.977 & 3.958 & 3.975 & 3.991 & 3.978 & 3.947 & 3.962 \\
\hline Std dev & & 0.111 & 0.150 & 0.101 & 0.101 & 0.113 & 0.149 & 0.139 \\
\hline Amount & 430543.410 & 10396.07 & 18608.55 & 19576.1 & 31479.4 & 21037.39 & 18635.8 & 23607.4 \\
\hline Trades & & 864 & 776 & 741 & 402 & 430 & 668 & 850 \\
\hline Perc & & 2.415 & 4.322 & 4.547 & 7.312 & 4.886 & 4.328 & 5.483 \\
\hline 2008 III & Market & IT0164 & IT0186 & IT0193 & IT0224 & IT0242 & IT0255 & IT0264 \\
\hline Rate & 4.218 & 4.234 & 4.211 & 4.245 & 4.247 & 4.227 & 4.205 & 4.205 \\
\hline Std dev & & 0.212 & 0.200 & 0.173 & 0.189 & 0.201 & 0.168 & 0.206 \\
\hline Amount & 373334.62 & 11000.6 & 11859.85 & 12843.8 & 20315.65 & 7512.4 & 23743.4 & 14840.7 \\
\hline Trades & & 607 & 454 & 1059 & 631 & 534 & 519 & 294 \\
\hline Perc & & 2.947 & 3.177 & 3.440 & 5.442 & 2.012 & 6.360 & 3.975 \\
\hline 2008 IV & Market & IT0164 & IT0175 & IT0224 & IT0255 & IT0269 & IT0279 & \\
\hline Rate & 3.061 & 3.043 & 3.105 & 3.157 & 2.923 & 3.024 & 2.852 & \\
\hline Std dev & & 0.680 & 0.580 & 0.617 & 0.547 & 0.379 & 0.585 & \\
\hline Amount & 301774.06 & 7350.9 & 6135.4 & $10,358.1$ & 12,520 & 9165.5 & 9972.85 & \\
\hline Trades & & 353 & 410 & 378 & 236 & 309 & 486 & \\
\hline Perc & & 2.436 & 2.033 & 3.432 & 4.149 & 3.037 & 3.305 & \\
\hline $2009 \mathrm{I}$ & Market & IT0173 & IT0190 & IT0193 & IT0203 & IT0208 & IT0224 & \\
\hline Rate & 1.234 & 1.332 & 1.269 & 1.154 & 1.116 & 1.203 & 1.159 & \\
\hline Std dev & & 0.400 & 0.409 & 0.241 & 0.295 & 0.454 & 0.333 & \\
\hline Amount & 236035.41 & 7710.5 & 7582.6 & 5605.81 & $19,758.5$ & 7993.2 & 10263.25 & \\
\hline Trades & & 376 & 361 & 490 & 500 & 681 & 367 & \\
\hline Perc & & 3.267 & 3.212 & 2.375 & 8.371 & 3.386 & 4.348 & \\
\hline 2009 II & Market & IT0175 & IT0193 & IT0224 & IT0260 & IT0261 & IT0279 & \\
\hline Rate & 0.668 & 0.653 & 0.656 & 0.660 & 0.762 & 0.714 & 0.649 & \\
\hline Std dev & & 0.224 & 0.234 & 0.234 & 0.247 & 0.179 & 0.244 & \\
\hline Amount & 263223.96 & 6146.1 & 6740.4 & 14973.45 & 13034.8 & 15428.81 & 13050.3 & \\
\hline Trades & & 404 & 554 & 603 & 502 & 217 & 574 & \\
\hline Perc & & 2.335 & 2.561 & 5.688 & 4.952 & 5.861 & 4.958 & \\
\hline
\end{tabular}


Table 10 continued

\begin{tabular}{lllllll}
\hline 2009 III & Market & IT0175 & IT0193 & IT0197 & IT0224 & IT0279 \\
\hline Rate & 0.329 & 0.330 & 0.323 & 0.296 & 0.335 & 0.340 \\
Std dev & & 0.051 & 0.065 & 0.043 & 0.056 & 0.069 \\
Amount & 193894.12 & 4600.65 & 6898.7 & 9605 & $12,577.7$ & 8897.45 \\
Trades & & 357 & 660 & 434 & 635 & 454 \\
Perc & & 2.373 & 3.558 & 4.954 & 6.487 & 4.589 \\
\hline 2009 IV & Market & IT0193 & IT0197 & IT0208 & IT0224 & IT0260 \\
\hline Rate & \multirow{2}{*}{0.295} & 0.298 & 0.277 & 0.274 & 0.307 & 0.310 \\
Std dev & & 0.053 & 0.041 & 0.056 & 0.044 & 0.063 \\
Amount & 224112.92 & 5025.95 & 17201.5 & 5390.9 & $10,915.23$ & 11945.75 \\
Trades & & 473 & 601 & 380 & 413 & 497 \\
Perc & & 2.243 & 7.675 & 2.405 & 4.870 & 5.330 \\
\hline
\end{tabular}

Rate mean rate, Std dev standard deviation of interest rate, Amount total amount lent, Perc market share of total amount traded, Trades number of trades

market is more concentrated on the demand side than on the supply side. In fact, the large borrowers control between 38 and $55 \%$ of traded volumes for the time span considered. This suggests that the key players have a tight grip on traded volumes both on the lending side and the demand side.

How stable is the composition of the group of key players? Tables 9 and 10 reveal a rich landscape of behaviors. First, identification of the key players confirms the marked changes in network structure that took place during the turmoil. There are substantial entry and exit dynamics in the two groups across time. For example, the percentage of long-lasting big lenders (i.e., present for more than four quarters) is $26 \%$; the corresponding figure for big borrowers is $41 \%$. This confirms our previous results indicating that the interbank market is not populated by actors with long-term strategies. Rather, large net-lending and net-borrowing decisions appear contingent on temporary factors, and are driven only by opportunistic behaviors and short-term strategies.

The changing ranks at the top layer of banks may be due to several factors. As stressed by Heider et al. (2009), cash hoarding is engaged for precautionary reasons during phases of market breakdown. Hence, banks that are large net cash suppliers at a given point in time may choose to reverse their course of action and become net borrowers. These banks may even choose to stay out of the market to avoid the adverse consequences of the increase in system-wide counterparty risk. The entry-exit dynamics displayed by the group of big borrowers is instead largely affected by the stigma that attaches to large demands for cash (see La Ganga and Vento 2010). Since the posting of ask trades in e-MID is public information, banks have an incentive to leave the platform during phases of market turbulence and opt for over-the-counter trading. 


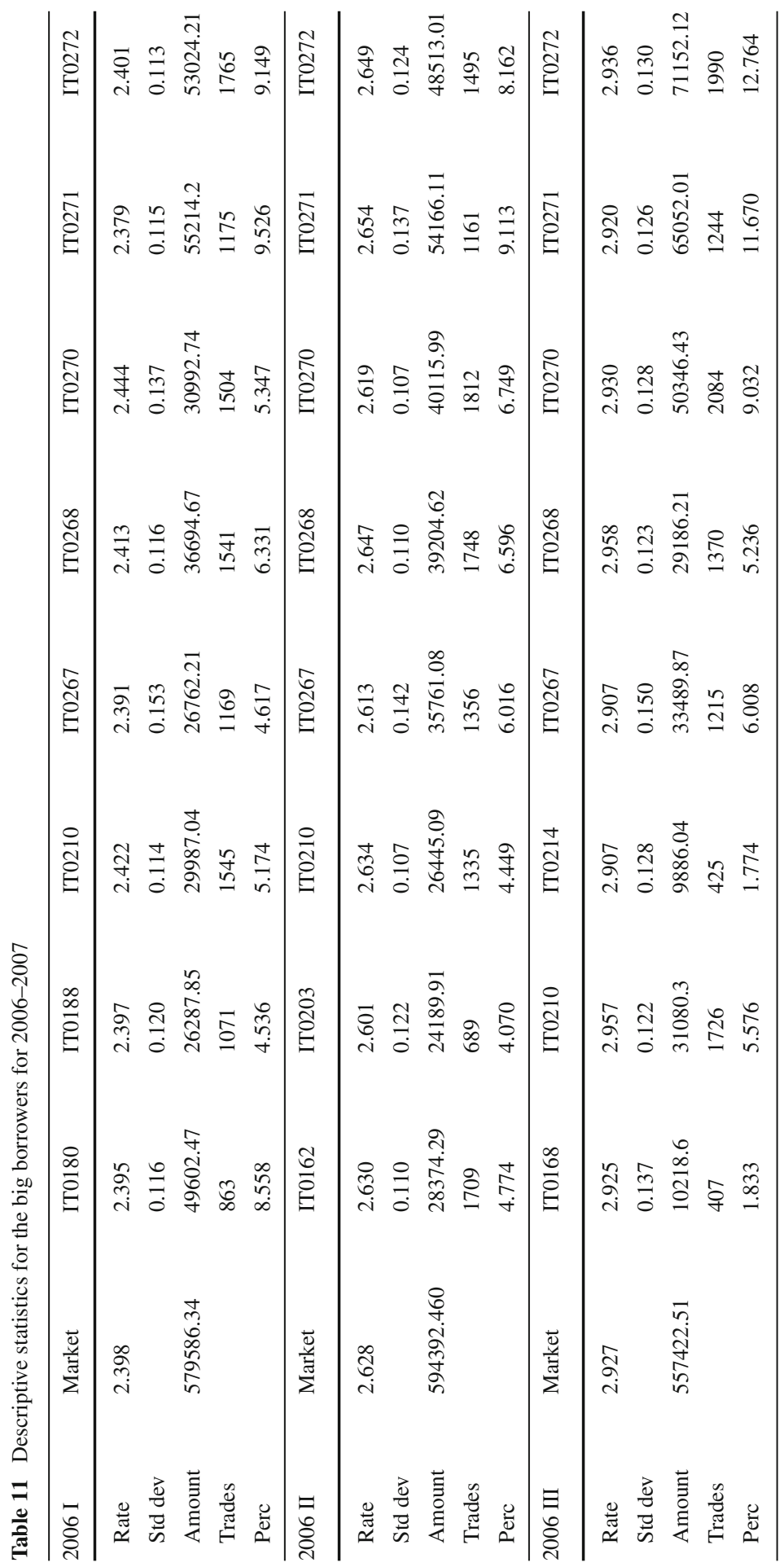




\begin{tabular}{|c|c|c|c|c|c|}
\hline $\begin{array}{l}\overrightarrow{\widehat{\sigma}} \\
\stackrel{0}{E}\end{array}$ & 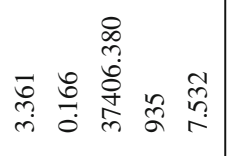 & 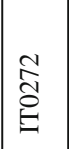 & 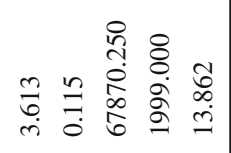 & \begin{tabular}{|l}
$\hat{N}$ \\
$\hat{\tilde{G}}$ \\
$\hat{E}$
\end{tabular} & 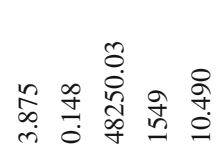 \\
\hline 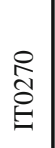 & 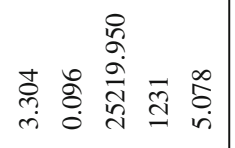 & $\overrightarrow{\hat{\delta}}$ & 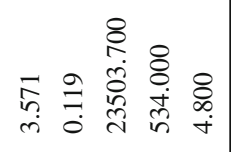 & $\mid \begin{array}{c}\stackrel{2}{\hat{~}} \\
\hat{\theta}\end{array}$ & 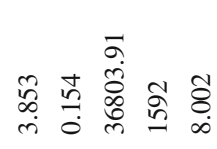 \\
\hline $\begin{array}{l}\infty \\
\stackrel{0}{1} \\
\stackrel{0}{\varrho}\end{array}$ & 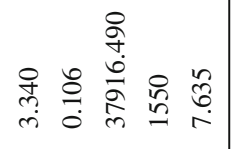 & 怘 & 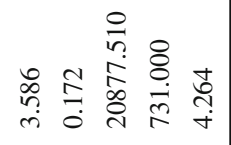 & 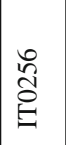 & 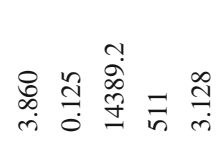 \\
\hline$\stackrel{\circ}{\stackrel{\mathrm{S}}{\mathrm{s}}}$ & 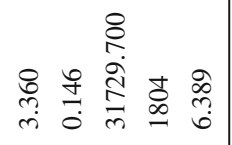 & 蒿 & 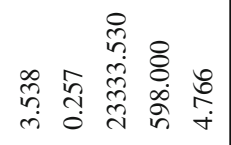 & $\stackrel{\circ}{\stackrel{\circ}{2}}$ & 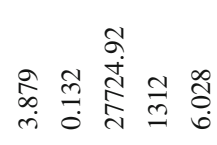 \\
\hline 总 & 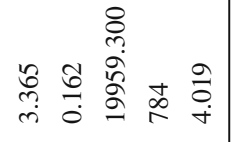 & 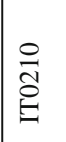 & 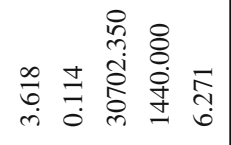 & \begin{tabular}{|l}
$\infty$ \\
$\stackrel{\infty}{0}$ \\
$\stackrel{0}{0}$ \\
\end{tabular} & 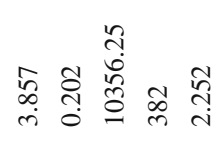 \\
\hline$\frac{\infty}{0}$ & 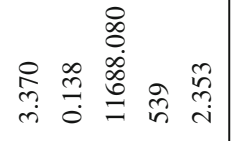 & 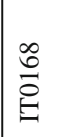 & 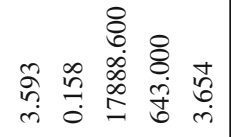 & $\begin{array}{l}\stackrel{n}{0} \\
\stackrel{0}{0} \\
\qquad\end{array}$ & 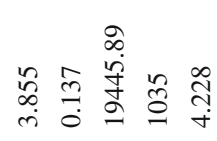 \\
\hline$\frac{1}{0}$ & 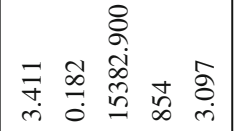 & \begin{tabular}{|l}
0 \\
$\stackrel{6}{0}$ \\
0 \\
\end{tabular} & 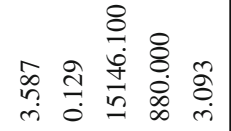 & 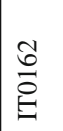 & 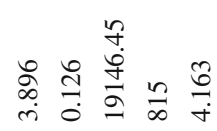 \\
\hline 离 & 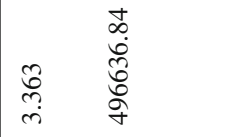 & \begin{tabular}{|l|}
$\overrightarrow{\bar{v}}$ \\
离 \\
\multirow{2}{*}{}
\end{tabular} & 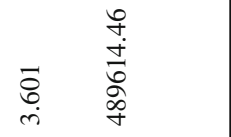 & 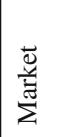 & 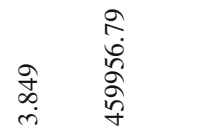 \\
\hline$z_{0}$ & 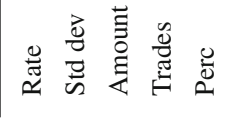 & 5 & 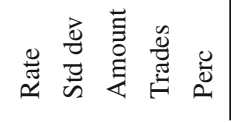 & 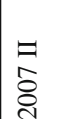 & 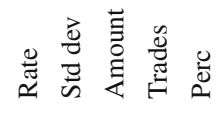 \\
\hline
\end{tabular}




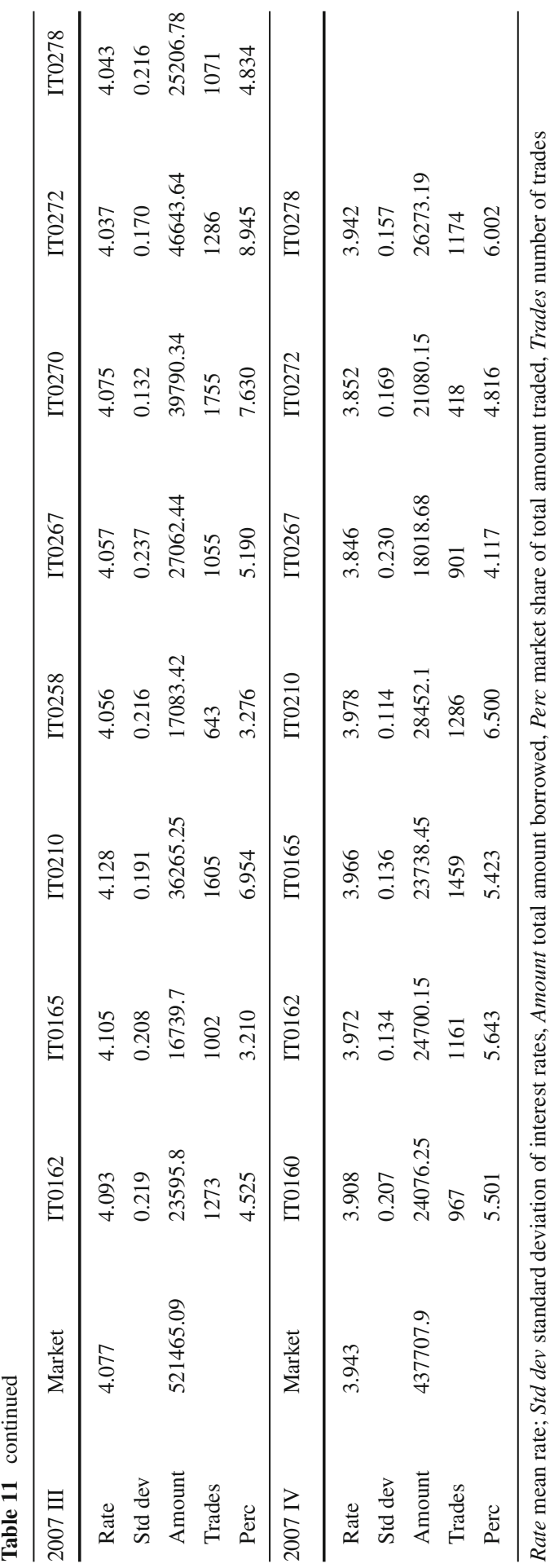


Table 12 Descriptive statistics for the big borrowers for 2008-2009

\begin{tabular}{|c|c|c|c|c|c|c|c|c|}
\hline $2008 \mathrm{I}$ & Market & IT0162 & IT0165 & IT0168 & IT0210 & IT0258 & IT0270 & IT0278 \\
\hline Rate & 4.04 & 4.046 & 4.058 & 4.036 & 4.042 & 4.061 & 4.022 & 4.039 \\
\hline Std dev & & 0.080 & 0.079 & 0.100 & 0.080 & 0.104 & 0.082 & 0.084 \\
\hline Amount & 405109.34 & 31604.6 & 27394.5 & 24446 & 18487.7 & 31544.49 & 22178.71 & 22094.95 \\
\hline Trades & & 1369 & 1837 & 848 & 902 & 1446 & 943 & 963 \\
\hline Perc & & 7.801 & 6.762 & 6.034 & 4.564 & 7.787 & 5.475 & 5.454 \\
\hline 2008 II & Market & IT0159 & IT0160 & IT0165 & IT0253 & IT0258 & IT0267 & IT0278 \\
\hline Rate & 3.971 & 3.940 & 3.972 & 3.994 & 3.946 & 3.970 & 3.959 & 3.987 \\
\hline Std dev & & 0.146 & 0.130 & 0.088 & 0.133 & 0.107 & 0.149 & 0.105 \\
\hline Amount & 430543.410 & 37007.06 & 22068.7 & 22238.7 & 39070 & 19124.52 & 19769.45 & 34495.2 \\
\hline Trades & & 1169 & 853 & 1353 & 883 & 873 & 947 & 1559 \\
\hline Perc & & 8.595 & 5.126 & 5.165 & 9.075 & 4.442 & 4.592 & 8.012 \\
\hline 2008 III & Market & IT0162 & IT0165 & IT0253 & IT0258 & IT0267 & IT0270 & IT0278 \\
\hline Rate & 4.218 & 4.214 & 4.262 & 4.117 & 4.233 & 4.199 & 4.163 & 4.262 \\
\hline Std dev & & 0.172 & 0.156 & 0.291 & 0.134 & 0.233 & 0.229 & 0.149 \\
\hline Amount & 373334.62 & 18738.7 & 15024.4 & 15395.85 & 17053 & 33971.9 & 19721.8 & 51083.3 \\
\hline Trades & & 956 & 972 & 307 & 748 & 822 & 885 & 2316 \\
\hline Perc & & 5.019 & 4.024 & 4.124 & 4.568 & 9.100 & 5.283 & 13.683 \\
\hline 2008 IV & Market & IT0159 & IT0160 & IT0165 & IT0237 & IT0253 & IT0267 & \\
\hline Rate & 3.061 & 3.061 & 3.044 & 3.097 & 3.984 & 3.146 & 3.268 & \\
\hline Std dev & & 0.484 & 0.618 & 0.571 & 0.394 & 0.389 & 0.615 & \\
\hline Amount & 301774.06 & 22376.42 & 17426.3 & 19842.6 & 15735.3 & 15705.9 & 41928.21 & \\
\hline Trades & & 608 & 924 & 1257 & 418 & 404 & 562 & \\
\hline Perc & & 7.415 & 5.775 & 6.575 & 5.214 & 5.205 & 13.894 & \\
\hline $2009 \mathrm{I}$ & Market & IT0160 & IT0165 & IT0168 & IT0265 & IT0270 & IT0284 & \\
\hline Rate & 1.234 & 1.370 & 1.276 & 1.040 & 1.150 & 1.023 & 1.072 & \\
\hline Std dev & & 0.435 & 0.421 & 0.224 & 0.354 & 0.298 & 0.255 & \\
\hline Amount & 236035.41 & 26875.4 & 16260.9 & 27433.3 & 21942.9 & $12,048.7$ & 16597.7 & \\
\hline Trades & & 1146 & 1116 & 1155 & 974 & 629 & 798 & \\
\hline Perc & & 11.386 & 6.889 & 11.623 & 9.296 & 5.105 & 7.032 & \\
\hline 2009 II & Market & IT0159 & IT0160 & IT0165 & IT0168 & IT0265 & IT0284 & \\
\hline Rate & 0.668 & 0.585 & 0.719 & 0.660 & 0.666 & 0.603 & 0.584 & \\
\hline Std dev & & 0.198 & 0.239 & 0.210 & 0.170 & 0.226 & 0.211 & \\
\hline Amount & 263223.96 & 16566 & 19573.9 & 16596.95 & 32762.1 & 22318.04 & 28710.7 & \\
\hline Trades & & 552 & 792 & 1034 & 1274 & 939 & 1151 & \\
\hline Perc & & 6.294 & 7.436 & 6.305 & 12.446 & 8.479 & 10.907 & \\
\hline
\end{tabular}


Table 12 continued

\begin{tabular}{lllllll}
\hline 2009 III & Market & IT0160 & IT0165 & IT0168 & IT0223 & IT0265 \\
\hline Rate & 0.329 & 0.356 & 0.312 & 0.296 & 0.355 & 0.291 \\
Std dev & & 0.061 & 0.050 & 0.050 & 0.070 & 0.044 \\
Amount & 193894.12 & 19757.3 & 9132.7 & 31526.19 & 6739.2 & 14031.09 \\
Trades & & 643 & 669 & 1405 & 729 & 639 \\
Perc & & 10.190 & 4.710 & 16.259 & 3.476 & 7.236 \\
\hline 2009 IV & Market & IT0159 & IT0160 & IT0168 & IT0265 & IT0284 \\
\hline Rate & 0.295 & 0.276 & 0.342 & 0.296 & 0.281 & 0.281 \\
Std dev & & 0.048 & 0.067 & 0.066 & 0.040 & 0.044 \\
Amount & 224112.92 & 26045.08 & 26743.25 & 38465.7 & 16226.9 & 17045 \\
Trades & & 922 & 967 & 1718 & 736 & 664 \\
Perc & & 11.621 & 11.933 & 17.164 & 7.241 & 7.606 \\
\hline
\end{tabular}

Rate mean rate, Std dev standard deviation of interest rates, Amount total amount borrowed, Perc market share of total amount traded, Trades number of trades

\subsection{Pricing interbank deposits and the key players}

The big lenders have market power over the distribution of money. In other words, their behavior determines how the ECB's money supply propagates through eMID. Hence, it is worth understanding whether the big lenders exploit their market power by engaging in pricing policies that are more aggressive, or "predatory", than those of other lenders. Two alternative and "extreme" hypotheses are proposed. On one hand, a bank that controls the relative supply of deposits within a network has the power to charge lending rates higher than the average rate. On the other, exchanges within a network may be driven by trust among counterparties (see, e.g., Cocco et al. 2009). Thus, a lender may refrain from charging above market rates to secure a "safer" demand for funds that carry below-average counterparty risk.

To investigate this issue, we compare the average interest rates big lenders demand from alternative classes of borrowers. We divide the borrowers in four groups based on the volume of funds they receive from each big lender. In practice, we compute the quartiles of the distribution of volumes borrowed, and classify the banks that borrow from the key lenders using the empirical quartiles. Group 1 includes those banks that borrow little, while Group 4 contains large borrowers. We then run an analysis of variance on the interest rates. We test whether a key player's lending rate to each group of borrowers is equal or lower than the overall group's average rate. The alternative hypothesis is that a key player's lending rate is larger than the average rate. We report the test results in Tables 13 and 14, where we denote by "rate group $n$ " the lending rate relative to the $n$th quartile of the distribution of volumes lent. The evidence suggests that there is a large variation in the key lenders' pricing 
Table 13 Average lending rates offered by the big lenders to four groups of borrowers (2006-2007)

\begin{tabular}{|c|c|c|c|c|c|c|c|c|}
\hline 2006 I & GR0006 & IT0185 & IT0187 & IT0257 & IT0258 & IT0259 & IT0269 & IT0278 \\
\hline$F$ & 0.270 & 3.176 & 2.951 & 1.636 & 2.094 & 4.290 & 5.868 & 1.076 \\
\hline$P$ value & 0.847 & 0.024 & 0.032 & 0.179 & 0.099 & 0.005 & 0.001 & 0.358 \\
\hline Rate Group 1 & & 2.397 & 2.375 & & 2.390 & 2.376 & 2.389 & \\
\hline Rate Group 2 & & 2.411 & 2.393 & & 2.385 & 2.449 & 2.380 & \\
\hline Rate Group 3 & & 2.460 & 2.402 & & 2.411 & 2.423 & 2.432 & \\
\hline Rate Group 4 & & 2.430 & 2.416 & & 2.410 & 2.411 & 2.420 & \\
\hline $2006 \mathrm{II}$ & IT0185 & IT0187 & IT0258 & IT0259 & IT0261 & IT0265 & IT0269 & IT0279 \\
\hline$F$ & 1.797 & 3.098 & 11.665 & 4.209 & 1.329 & 0.393 & 2.426 & 8.433 \\
\hline$P$ value & 0.147 & 0.026 & 0.000 & 0.006 & 0.264 & 0.758 & 0.064 & 0.000 \\
\hline Rate Group 1 & & 2.670 & 2.609 & 2.656 & & & 2.622 & 2.634 \\
\hline Rate Group 2 & & 2.622 & 2.672 & 2.688 & & & 2.599 & 2.715 \\
\hline Rate Group 3 & & 2.613 & 2.628 & 2.672 & & & 2.608 & 2.653 \\
\hline Rate Group 4 & & 2.630 & 2.601 & 2.638 & & & 2.622 & 2.658 \\
\hline $2006 \mathrm{III}$ & IT0193 & IT0258 & IT0259 & IT0261 & IT0263 & IT0265 & IT0269 & IT0279 \\
\hline$F$ & 2.244 & 0.269 & 0.326 & 0.580 & 0.754 & 2.654 & 5.112 & 10.613 \\
\hline$P$ value & 0.082 & 0.848 & 0.807 & 0.628 & 0.521 & 0.049 & 0.002 & 0.000 \\
\hline Rate Group 1 & 2.979 & & & & & 2.906 & 2.949 & 2.828 \\
\hline Rate Group 2 & 2.921 & & & & & 2.812 & 2.940 & 2.927 \\
\hline Rate Group 3 & 2.956 & & & & & 2.921 & 2.894 & 2.918 \\
\hline Rate Group 4 & 2.937 & & & & & 2.923 & 2.927 & 2.917 \\
\hline 2006 IV & GR0006 & IT0173 & IT0187 & IT0193 & IT0242 & IT0265 & IT0269 & IT0279 \\
\hline$F$ & 0.689 & 0.756 & 2.035 & 0.447 & 5.942 & 1.127 & 2.963 & 1.190 \\
\hline$P$ value & 0.559 & 0.519 & 0.108 & 0.719 & 0.001 & 0.339 & 0.031 & 0.312 \\
\hline Rate Group 1 & & & 3.324 & & 3.407 & & 3.419 & \\
\hline Rate Group 2 & & & 3.401 & & 3.452 & & 3.372 & \\
\hline Rate Group 3 & & & 3.381 & & 3.437 & & 3.352 & \\
\hline Rate Group 4 & & & 3.384 & & 3.377 & & 3.350 & \\
\hline 2007 I & IT0187 & IT0193 & IT0198 & IT0257 & IT0261 & IT0269 & IT0279 & \\
\hline$F$ & 2.158 & 3.494 & 1.189 & 1.117 & 0.273 & 0.324 & 1.234 & \\
\hline$P$ value & 0.091 & 0.015 & 0.313 & 0.341 & 0.845 & 0.808 & 0.296 & \\
\hline Rate Group 1 & 3.578 & 3.601 & & & & & & \\
\hline Rate Group 2 & 3.616 & 3.581 & & & & & & \\
\hline Rate Group 3 & 3.623 & 3.581 & & & & & & \\
\hline Rate Group 4 & 3.612 & 3.623 & & & & & & \\
\hline
\end{tabular}


Table 13 continued

\begin{tabular}{|c|c|c|c|c|c|c|c|c|}
\hline 2007 II & IT0185 & IT0187 & IT0208 & IT0257 & IT0261 & IT0269 & IT0279 & \\
\hline$F$ & 2.249 & 1.731 & 6.314 & 5.444 & 0.327 & 3.956 & 0.397 & \\
\hline$P$ value & 0.082 & 0.159 & 0.000 & 0.001 & 0.806 & 0.008 & 0.756 & \\
\hline Rate Group 1 & 3.917 & & 3.952 & 3.857 & & 3.907 & & \\
\hline Rate Group 2 & 3.867 & & 3.873 & 3.870 & & 3.814 & & \\
\hline Rate Group 3 & 3.878 & & 3.869 & 3.876 & & 3.837 & & \\
\hline Rate Group 4 & 3.871 & & 3.831 & 3.837 & & 3.816 & & \\
\hline 2007 III & IT0187 & IT0193 & IT0208 & IT0224 & IT0255 & IT0261 & IT0269 & IT0279 \\
\hline$F$ & 1.720 & 1.184 & 3.722 & 4.969 & 0.492 & 1.118 & 3.844 & 1.673 \\
\hline$P$ value & 0.161 & 0.315 & 0.011 & 0.002 & 0.688 & 0.341 & 0.009 & 0.171 \\
\hline Rate Group 1 & & & 4.191 & 3.980 & & & 4.081 & \\
\hline Rate Group 2 & & & 4.121 & 4.078 & & & 4.093 & \\
\hline Rate Group 3 & & & 4.070 & 4.065 & & & 4.074 & \\
\hline Rate Group 4 & & & 4.073 & 4.116 & & & 4.040 & \\
\hline 2007 IV & IT0187 & IT0193 & IT0224 & IT0255 & IT0261 & IT0269 & IT0279 & \\
\hline$F$ & 7.792 & 1.968 & 0.659 & 2.227 & 1.414 & 5.411 & 0.286 & \\
\hline$P$ value & 0.000 & 0.117 & 0.577 & 0.084 & 0.237 & 0.001 & 0.836 & \\
\hline Rate Group 1 & 3.858 & & & 3.984 & & 3.996 & & \\
\hline Rate Group 2 & 3.972 & & & 3.978 & & 3.956 & & \\
\hline Rate Group 3 & 3.980 & & & 3.970 & & 3.920 & & \\
\hline Rate Group 4 & 3.971 & & & 3.932 & & 3.909 & & \\
\hline
\end{tabular}

$F$ test of the analysis of variance, $P$ value probability of the $F$ test, Rate Group 1-Rate Group 4 average rates of the 4 group of borrowers

behavior across time. In 2006, the big lenders that exhibit higher average lending rates in the market are those engaged in aggressive pricing behavior. This pattern reverses during 2007 until the second quarter of the 2008 and it turns again during 2009.

We also look at whether big borrowers are drivers for the borrowing rates. In this case, we are interested in understanding whether the key borrowers pay aboveaverage interest rates in a systematic manner. Tables 15 and 16 report the average borrowing rates offered by four groups of lenders. These groups are again identified from the quartiles of the distribution of volumes borrowed. We test the null of equality between the borrowing rates of each key borrower from each lender group and the average rate for the group itself. The alternative hypothesis is that the former rate is higher than the latter. Within the class of big borrowers, different banks receive different treatment from alternative groups of counterparties. Tables 15 and 16 show that larger net borrowers pay higher interest rates. This pattern was observable before the beginning of the turmoil and becomes more evident after 2007. 
Table 14 Average lending rates offered by the big lenders to four groups of borrowers (2008-2009)

\begin{tabular}{|c|c|c|c|c|c|c|c|}
\hline $2008 \mathrm{I}$ & IT0193 & IT0224 & IT0255 & IT0264 & IT0269 & IT0279 & \\
\hline$F$ & 0.857 & 1.539 & 2.389 & 0.955 & 0.774 & 0.971 & \\
\hline$P$ value & 0.463 & 0.203 & 0.068 & 0.414 & 0.509 & 0.406 & \\
\hline Rate Group 1 & & & 4.032 & & & & \\
\hline Rate Group 2 & & & 4.045 & & & & \\
\hline Rate Group 3 & & & 4.016 & & & & \\
\hline Rate Group 4 & & & 4.033 & & & & \\
\hline 2008 II & IT0193 & IT0198 & IT0224 & IT0255 & IT0261 & IT0269 & IT0279 \\
\hline$F$ & 0.628 & 6.515 & 1.136 & 1.132 & 8.453 & 1.763 & 0.379 \\
\hline$P$ value & 0.597 & 0.000 & 0.334 & 0.336 & 0.000 & 0.153 & 0.768 \\
\hline Rate Group 1 & & 3.994 & & & 3.876 & & \\
\hline Rate Group 2 & & 3.974 & & & 3.987 & & \\
\hline Rate Group 3 & & 3.984 & & & 3.977 & & \\
\hline Rate Group 4 & & 3.936 & & & 3.987 & & \\
\hline 2008 III & IT0164 & IT0186 & IT0193 & IT0224 & IT0242 & IT0255 & IT0264 \\
\hline$F$ & 1.146 & 5.000 & 6.424 & 4.807 & 0.045 & 1.738 & 0.570 \\
\hline PROB & 0.330 & 0.002 & 0.000 & 0.003 & 0.987 & 0.158 & 0.635 \\
\hline Rate Group 1 & & 4.004 & 4.286 & 4.150 & & & \\
\hline Rate Group 2 & & 4.230 & 4.257 & 4.217 & & & \\
\hline Rate Group 3 & & 4.215 & 4.271 & 4.240 & & & \\
\hline Rate Group 4 & & 4.215 & 4.223 & 4.268 & & & \\
\hline 2008 IV & IT0164 & IT0175 & IT0224 & IT0255 & IT0269 & IT0279 & \\
\hline$F$ & 8.847 & 3.826 & 2.092 & 1.183 & 0.717 & 1.867 & \\
\hline$P$ value & 0.000 & 0.010 & 0.101 & 0.317 & 0.543 & 0.134 & \\
\hline Rate Group 1 & 2.595 & 2.923 & 2.870 & & & & \\
\hline Rate Group 2 & 3.029 & 3.032 & 3.156 & & & & \\
\hline Rate Group 3 & 2.830 & 3.239 & 3.212 & & & & \\
\hline Rate Group 4 & 3.186 & 3.066 & 3.165 & & & & \\
\hline 2009 I & IT0173 & IT0190 & IT0193 & IT0203 & IT0208 & IT0224 & \\
\hline$F$ & 8.482 & 2.895 & 1.700 & 4.211 & 3.355 & 6.745 & \\
\hline$P$ value & 0.000 & 0.035 & 0.166 & 0.006 & 0.019 & 0.000 & \\
\hline Rate Group 1 & 1.136 & 1.500 & & 1.122 & 1.154 & 1.228 & \\
\hline Rate Group 2 & 1.392 & 1.229 & & 1.091 & 1.210 & 0.992 & \\
\hline Rate Group 3 & 1.469 & 1.216 & & 1.043 & 1.271 & 1.087 & \\
\hline Rate Group 4 & 1.255 & 1.269 & & 1.153 & 1.149 & 1.209 & \\
\hline
\end{tabular}


Table 14 continued

\begin{tabular}{lllllll}
\hline 2009 II & IT0175 & IT0193 & IT0224 & IT0260 & IT0261 & IT0279 \\
\hline$F$ & 4.294 & 1.223 & 0.954 & 3.549 & 5.067 & 5.780 \\
$P$ value & 0.005 & 0.301 & 0.414 & 0.014 & 0.002 & 0.001 \\
Rate Group 1 & 0.562 & & & 0.823 & 0.798 & 0.614 \\
Rate Group 2 & 0.643 & & & 0.743 & 0.823 & 0.580 \\
Rate Group 3 & 0.576 & & & 0.696 & 0.706 & 0.614 \\
Rate Group 4 & 0.673 & & & 0.784 & 0.689 & 0.685 \\
\hline 2009 III & IT0175 & IT0193 & IT0197 & IT0224 & IT0279 & \\
\hline$F$ & 1.069 & 0.064 & 1.375 & 3.530 & 14.975 & \\
$P$ value & 0.362 & 0.979 & 0.250 & 0.015 & 0.000 & \\
Rate Group 1 & & & & 0.330 & 0.301 & \\
Rate Group 2 & & & & 0.342 & 0.327 & \\
Rate Group 3 & & & & 0.322 & 0.312 & \\
Rate Group 4 & & & & 0.339 & 0.356 & \\
\hline 2009 IV & IT0193 & IT0197 & IT0208 & IT0224 & IT0260 & \\
\hline$F$ & & & & & \\
$P$ value & 0.748 & \multirow{2}{*}{1.221} & 9.103 & 1.299 & 15.070 & \\
Rate Group 1 & & 0.301 & 0.000 & 0.274 & 0.000 & \\
Rate Group 2 & & & 0.250 & & 0.386 & \\
Rate Group 3 & & & 0.314 & & 0.334 & \\
Rate Group 4 & & & 0.271 & & 0.290 & \\
$F F$ Ies of the a & & & & 0.310 & \\
\hline
\end{tabular}

$F$ test of the analysis of variance, $P$ value probability of the $F$ test, Rate Group 1 -Rate Group 4 average rates of the 4 group of borrowers

What are the economic implications of our findings? The identification of key players emphasizes the uneven access to money in the interbank market. In the presence of consolidated network links between financial institutions, a buoyant supply of cash from the central bank may not necessarily "pass through" the system if key players take advantage of market bottlenecks. Therefore, during periods of market stress, even through a central bank might lower the benchmark rate, the market may not show improvement in terms of traded volumes. We find that large net lenders in e-MID exploit their "market power" in the supply of cash to the interbank market.

\subsection{Robustness analysis}

To investigate the robustness of our modeling approach, we derive a list of key players based on each of the five values of $\alpha$. We repeat the analysis carried out in the body of 
Table 15 Average interest rates paid by the big borrowers on loans from four groups of lenders (2006-2007)

\begin{tabular}{|c|c|c|c|c|c|c|c|c|}
\hline $2006 \mathrm{I}$ & IT0180 & IT0188 & IT0210 & IT0267 & IT0268 & IT0270 & IT0271 & IT0272 \\
\hline$F$ & 5.778 & 1.021 & 2.255 & 10.832 & 4.321 & 6.456 & 0.887 & 1.446 \\
\hline$P$ value & 0.001 & 0.382 & 0.080 & 0.000 & 0.005 & 0.000 & 0.447 & 0.228 \\
\hline Rate Group 1 & 2.407 & & 2.397 & 2.300 & 2.378 & 2.422 & & \\
\hline Rate Group 2 & 2.345 & & 2.410 & 2.356 & 2.406 & 2.482 & & \\
\hline Rate Group 3 & 2.409 & & 2.430 & 2.376 & 2.427 & 2.434 & & \\
\hline Rate Group 4 & 2.395 & & 2.422 & 2.406 & 2.409 & 2.442 & & \\
\hline $2006 \mathrm{II}$ & IT0162 & IT0203 & IT0210 & IT0267 & IT0268 & IT0270 & IT0271 & IT0272 \\
\hline$F$ & 1.375 & 5.226 & 4.604 & 6.083 & 4.582 & 1.811 & 1.291 & 0.712 \\
\hline$P$ value & 0.249 & 0.001 & 0.003 & 0.000 & 0.003 & 0.143 & 0.276 & 0.545 \\
\hline Rate Group 1 & & 2.519 & 2.659 & 2.559 & 2.646 & & & \\
\hline Rate Group 2 & & 2.610 & 2.630 & 2.592 & 2.640 & & & \\
\hline Rate Group 3 & & 2.600 & 2.617 & 2.596 & 2.632 & & & \\
\hline Rate Group 4 & & 2.606 & 2.640 & 2.623 & 2.654 & & & \\
\hline 2006 III & IT0168 & IT0210 & IT0214 & IT0267 & IT0268 & IT0270 & IT0271 & IT0272 \\
\hline$F$ & 2.455 & 11.990 & 3.713 & 8.992 & 4.046 & 1.608 & 0.260 & 0.151 \\
\hline$P$ value & 0.063 & 0.000 & 0.012 & 0.000 & 0.007 & 0.186 & 0.854 & 0.929 \\
\hline Rate Group 1 & 2.850 & 2.978 & 2.913 & 2.798 & 2.962 & & & \\
\hline Rate Group 2 & 2.932 & 3.001 & 2.942 & 2.904 & 2.979 & & & \\
\hline Rate Group 3 & 2.937 & 2.956 & 2.926 & 2.910 & 2.974 & & & \\
\hline Rate Group 4 & 2.926 & 2.947 & 2.890 & 2.913 & 2.950 & & & \\
\hline 2006 IV & IT0162 & IT0168 & IT0203 & IT0210 & IT0268 & IT0270 & IT0271 & IT0272 \\
\hline$F$ & 6.314 & 0.195 & 3.494 & 6.158 & 2.395 & 3.389 & 1.596 & 5.531 \\
\hline$P$ value & 0.000 & 0.900 & 0.015 & 0.000 & 0.067 & 0.017 & 0.189 & 0.001 \\
\hline Rate Group 1 & 3.350 & & 3.303 & 3.337 & & & & 3.385 \\
\hline Rate Group 2 & 3.386 & & 3.380 & 3.353 & & & & 3.405 \\
\hline Rate Group 3 & 3.451 & & 3.349 & 3.344 & & & & 3.433 \\
\hline Rate Group 4 & 3.402 & & 3.372 & 3.375 & & & & 3.391 \\
\hline 2007 I & IT0162 & IT0168 & IT0210 & IT0254 & IT0256 & IT0271 & IT0272 & \\
\hline$F$ & 5.937 & 4.060 & 4.188 & 6.667 & 2.373 & 1.376 & 2.204 & \\
\hline$P$ value & 0.001 & 0.007 & 0.006 & 0.000 & 0.069 & 0.249 & 0.086 & \\
\hline Rate Group 1 & 3.540 & 3.499 & 3.604 & 3.415 & 3.554 & & 3.617 & \\
\hline Rate Group 2 & 3.568 & 3.598 & 3.593 & 3.460 & 3.543 & & 3.611 & \\
\hline Rate Group 3 & 3.576 & 3.593 & 3.625 & 3.533 & 3.595 & & 3.624 & \\
\hline Rate Group 4 & 3.602 & 3.599 & 3.621 & 3.568 & 3.592 & & 3.608 & \\
\hline
\end{tabular}


Table 15 continued

\begin{tabular}{|c|c|c|c|c|c|c|c|c|}
\hline 2007 II & IT0162 & IT0165 & IT0168 & IT0210 & IT0256 & IT0270 & IT0272 & \\
\hline$F$ & 0.797 & 0.952 & 1.700 & 3.805 & 3.818 & 0.695 & 0.539 & \\
\hline$P$ value & 0.496 & 0.415 & 0.166 & 0.010 & 0.010 & 0.555 & 0.656 & \\
\hline Rate Group 1 & & & & 3.850 & 3.786 & & & \\
\hline Rate Group 2 & & & & 3.911 & 3.884 & & & \\
\hline Rate Group 3 & & & & 3.871 & 3.870 & & & \\
\hline Rate Group 4 & & & & 3.879 & 3.856 & & & \\
\hline 2007 III & IT0162 & IT0165 & IT0210 & IT0258 & IT0267 & IT0270 & IT0272 & IT0278 \\
\hline$F$ & 1.403 & 2.145 & 1.019 & 0.505 & 2.089 & 0.458 & 0.691 & 5.262 \\
\hline$P$ value & 0.240 & 0.093 & 0.383 & 0.679 & 0.100 & 0.712 & 0.558 & 0.001 \\
\hline Rate Group 1 & & 4.146 & & & 4.041 & & & \\
\hline Rate Group 2 & & 4.127 & & & 4.090 & & & \\
\hline Rate Group 3 & & 4.088 & & & 4.029 & & & \\
\hline Rate Group 4 & & 4.102 & & & 4.064 & & & \\
\hline 2007 IV & IT0160 & IT0162 & IT0165 & IT0210 & IT0267 & IT0272 & IT0278 & \\
\hline$F$ & 9.271 & 0.064 & 4.086 & 3.394 & 20.041 & 4.578 & 2.703 & \\
\hline$P$ value & 0.000 & 0.979 & 0.007 & 0.017 & 0.000 & 0.004 & 0.044 & \\
\hline Rate Group 1 & 3.739 & & 3.920 & 3.945 & 3.615 & 3.751 & 3.921 & \\
\hline Rate Group 2 & 3.902 & & 3.946 & 3.966 & 3.749 & 3.816 & 3.915 & \\
\hline Rate Group 3 & 3.903 & & 3.971 & 3.988 & 3.845 & 3.870 & 3.955 & \\
\hline Rate Group 4 & 3.923 & & 3.971 & 3.979 & 3.873 & 3.864 & 3.945 & \\
\hline
\end{tabular}

$F$ test of the Analysis of Variance, $P$ value probability of the $F$ test, Rate Group 1-Rate Group 4 average rates of the 4 group of lenders

the paper and compare the results on bank pricing policies. For the largest number of quarters, we find that the value $\alpha=0.5$ allows detecting the highest number of banks that charge above-average lending rates. Hence, for $\alpha=0.5$, banks lend/borrow money at a price higher than the market price on average in 12 of the 16 periods considered. Overall, the proportions of banks demanding/paying above-average rates are equal to $55.59 \%$ for $\alpha=0.5,48.25 \%$ for $\alpha=0.75,1,44.76 \%$ for $\alpha=0$, and $40.77 \%$ for $\alpha=0.25$.

\section{Conclusion}

Extant work on network effects in the money market studies short-term relations between banks. In this paper, we focus on the long-term patterns of network formation. Using a dataset from the electronic platform e-MID, we provide evidence of evolving relations that induced an uneven distribution of cash between banks 
Table 16 Average interest rates paid by the big borrowers on loans from four groups of lenders (2008-2009)

\begin{tabular}{|c|c|c|c|c|c|c|c|}
\hline 2008 I & IT0162 & IT0165 & IT0168 & IT0210 & IT0258 & IT0270 & IT0278 \\
\hline$F$ & 3.695 & 3.142 & 2.537 & 0.995 & 6.547 & 1.302 & 0.585 \\
\hline$P$ value & 0.011 & 0.024 & 0.055 & 0.395 & 0.000 & 0.273 & 0.625 \\
\hline Rate Group 1 & 4.011 & 4.074 & 4.030 & & 4.107 & & \\
\hline Rate Group 2 & 4.056 & 4.049 & 4.051 & & 4.076 & & \\
\hline Rate Group 3 & 4.046 & 4.057 & 4.049 & & 4.057 & & \\
\hline Rate Group 4 & 4.046 & 4.060 & 4.030 & & 4.055 & & \\
\hline 2008 II & IT0159 & IT0160 & IT0165 & IT0253 & IT0258 & IT0267 & IT0278 \\
\hline$F$ & 2.163 & 1.844 & 1.945 & 3.245 & 1.104 & 4.565 & 1.513 \\
\hline$P$ value & 0.091 & 0.138 & 0.120 & 0.021 & 0.347 & 0.003 & 0.209 \\
\hline Rate Group 1 & 3.903 & & & 3.920 & & 3.878 & \\
\hline Rate Group 2 & 3.956 & & & 3.912 & & 3.956 & \\
\hline Rate Group 3 & 3.944 & & & 3.953 & & 3.959 & \\
\hline Rate Group 4 & 3.937 & & & 3.952 & & 3.966 & \\
\hline 2008 III & IT0162 & IT0165 & IT0253 & IT0258 & IT0267 & IT0270 & IT0278 \\
\hline$F$ & 5.757 & 1.336 & 0.453 & 3.204 & 3.095 & 3.811 & 1.846 \\
\hline$P$ value & 0.001 & 0.261 & 0.715 & 0.023 & 0.026 & 0.010 & 0.137 \\
\hline Rate Group 1 & 4.128 & & & 4.238 & 4.118 & 4.057 & \\
\hline Rate Group 2 & 4.173 & & & 4.193 & 4.181 & 4.158 & \\
\hline Rate Group 3 & 4.209 & & & 4.245 & 4.172 & 4.146 & \\
\hline Rate Group 4 & 4.227 & & & 4.236 & 4.216 & 4.179 & \\
\hline 2008 IV & IT0159 & IT0160 & IT0165 & IT0237 & IT0253 & IT0267 & \\
\hline$F$ & 1.315 & 3.015 & 3.599 & 8.018 & 1.676 & 30.908 & \\
\hline$P$ value & 0.268 & 0.029 & 0.013 & 0.000 & 0.172 & 0.000 & \\
\hline Rate Group 1 & & 3.288 & 3.046 & 3.813 & & 3.783 & \\
\hline Rate Group 2 & & 3.047 & 3.212 & 3.901 & & 3.755 & \\
\hline Rate Group 3 & & 2.980 & 3.070 & 3.946 & & 3.848 & \\
\hline Rate Group 4 & & 3.076 & 3.079 & 4.082 & & 3.167 & \\
\hline $2009 \mathrm{I}$ & IT0160 & IT0165 & IT0168 & IT0265 & IT0270 & IT0284 & \\
\hline$F$ & 23.238 & 3.509 & 2.676 & 3.901 & 2.603 & 0.966 & \\
\hline$P$ value & 0.000 & 0.015 & 0.046 & 0.009 & 0.051 & 0.408 & \\
\hline Rate Group 1 & 1.654 & 1.435 & 1.119 & 1.257 & 1.107 & & \\
\hline Rate Group 2 & 1.245 & 1.293 & 1.060 & 1.218 & 0.971 & & \\
\hline Rate Group 3 & 1.318 & 1.296 & 1.037 & 1.133 & 0.995 & & \\
\hline Rate Group 4 & 1.439 & 1.243 & 1.032 & 1.129 & 1.044 & & \\
\hline
\end{tabular}


Table 16 continued

\begin{tabular}{|c|c|c|c|c|c|c|}
\hline 2009 II & IT0159 & IT0160 & IT0165 & IT0168 & IT0265 & IT0284 \\
\hline$F$ & 1.623 & 1.498 & 1.918 & 0.597 & 0.552 & 7.034 \\
\hline$P$ value & 0.183 & 0.214 & 0.125 & 0.617 & 0.647 & 0.000 \\
\hline Rate Group 1 & & & & & & 0.622 \\
\hline Rate Group 2 & & & & & & 0.533 \\
\hline Rate Group 3 & & & & & & 0.570 \\
\hline Rate Group 4 & & & & & & 0.607 \\
\hline 2009 III & IT0160 & IT0165 & IT0168 & IT0223 & IT0265 & \\
\hline$F$ & 4.934 & 2.657 & 2.761 & 7.834 & 2.693 & \\
\hline$P$ value & 0.002 & 0.047 & 0.041 & 0.000 & 0.045 & \\
\hline Rate Group 1 & 0.344 & 0.319 & 0.293 & 0.363 & 0.281 & \\
\hline Rate Group 2 & 0.363 & 0.299 & 0.293 & 0.357 & 0.282 & \\
\hline Rate Group 3 & 0.369 & 0.317 & 0.292 & 0.338 & 0.290 & \\
\hline Rate Group 4 & 0.349 & 0.312 & 0.300 & 0.366 & 0.294 & \\
\hline 2009 IV & IT0160 & IT0165 & IT0168 & IT0223 & IT0265 & \\
\hline$F$ & 1.694 & 6.406 & 1.678 & 1.418 & 0.068 & \\
\hline$P$ value & 0.167 & 0.000 & 0.170 & 0.238 & 0.977 & \\
\hline Rate Group 1 & & 0.321 & & & & \\
\hline Rate Group 2 & & 0.323 & & & & \\
\hline Rate Group 3 & & 0.301 & & & & \\
\hline Rate Group 4 & & 0.288 & & & & \\
\hline
\end{tabular}

$F$ test of the analysis of variance, $P$ value probability of the $F$ test, Rate Group 1 -Rate Group 4 average rates of the 4 group of lenders

during the recent financial turmoil. These patterns of exchange are largely asymmetric and imply a clear division of roles between lenders and borrowers. We identify key players that affect the demand and supply sides of the market and consider the implications of their pricing strategies. We find that the banks driving the supply of interbank deposits do, indeed, exploit their market power by imposing additional interest-rate charges. At the same time, the large borrowers pay above-average rates.

Our results are a starting point for future research. First, available panel-data methods could be used to estimate loan demand and supply in the Euro interbank market. A study of supply and demand shocks would shed light on the drivers of the market. Look at each bank's contribution to these aggregate shocks would be of interest. The idea of relationship lending could be formalized in the form of anticipated persistent shocks to the supply of cash.

This would allow formally testing for the pricing effects of these shocks. In this paper, we disregard the explicit role of the primary supply of money. However, a study 
that investigates whether the interbank market is driven by key players at a higher frequency, for instance, at a weekly frequency, would allow factoring in the indirect effect of the ECB's liquidity supply on network relations.

Since the issue of systemic risk has become very important, providing networkbased measures for the risk of contagion would be very helpful. Alternative methodologies could be employed to study whether the big players can be a source of systemic risk, thus contributing to network disruptions. For this purpose, it would be relevant to study how big players contribute to the probability of network fragmentation.

Babus (2006) suggests that interbank networks are formed between banks that are privy to information about counterparty risk, or "risk of contagion". In future work, we are planning to compute formal measures of asymmetric information, such as the probability of informed trading (see Easley and O'Hara 1987). We can then study the relation between asymmetric information and indicators of network structure. Since information is often argued to be a determinant of asset prices (see, e.g., Easley et al. 2002), we can also investigate the joint contribution of private information and network centrality to the determination of interbank rates.

Acknowledgments The authors acknowledge helpful comments from seminar participants at the Bank of Finland. They are also very grateful to Stefano Nardelli and to an anonymous referee for very insightful suggestions that led to major improvements of the paper. Tatjana Berg provided very valuable editorial assistance. Marzo and Zagaglia received financial support through a PRIN Grant by the Ministry of Education and Research at the University of Bologna.

\section{References}

Adamic, L., Brunetti, C., Harris, J., Kirilenko, A.: “Trading networks,” Manuscript, University of Michigan, Johns Hopkins University, University of Delaware, and Commodity Futures Trading Commission (2010)

Angelini, P., Nobili, A., Picillo, C.: The interbank market after August 2007: What has changed, and why? J. Money Credit Banking 43(5), 923-958 (2011)

Babus, A.: "The formation of financial networks," Discussion Paper 093/2, Tinbergen Institute (2006)

Barabasi, A., Reka, A.: Emergence of scaling in random networks. Science 286, 509-512 (1999)

Barrat, A., Barthelemy, M., Pastor-Satorras, R., Vespignani, A.: The architecture of complex weighted networks. PNAS 101(11), 3747-3752 (2004)

Bech, M., Atalay, E.: The topology of the federal funds market. Federal Reserve Bank of New York, Staff Reports, 354 (2008)

Borgatti, M., Jones, C., Everett, M.: Network measures of social capital. Connections 21, 27-36 (1998)

Borgatti, S.: Identifying sets of key players in a social network. Comput. Math. Organ. Theory 12, 21-34 (2006)

Borgatti, S.P., Mehra, A., Brass, D.J., Labianca, G.: Network analysis in the social sciences. Science 323(5916), 892-895 (2009)

Brunetti, C., Di Filippo, M., Harris, J.H.: Effects of central bank intervention on the interbank market during the subprime crisis. Rev. Finan. Stud. 24(6), 2053-2083 (2011)

Burt, R.: Structural holes: The social structure of competition. Harvard University Press, Cambridge (1992)

Butts, C.: Social network analysis with SNA. J. Stat. Softw. 24(6), 1-51 (2008)

Butts, C.: SNA: Tools for social network analysis. R package, version 2.1 (2010)

Carrington, P., Scott, J., Wasserman, S.: Models and methods in social network analysis. Cambridge University Press, New York (2005)

Cassola, N., Morana, C.: Comovements in volatility in the Euro money market. J. Int. Money Finance 29(3), 525-539 (2010) 
Clauset, A., Shazili, C., Newman, M.: Power-law distributions in empirical data. SIAM Rev. 51, 661-703 (2009)

Cocco, J., Gomes, F.J., Martins, N.C.: Lending relationships in the interbank market. J. Finan. Intermed. 18(1), 24-48 (2009)

Craig, B., Fecht, F., Tumer-Alkan, G.: "The role of interbank relationships and liquidity needs," Deutsche Bundesbank Discussion Paper 54/2013 (2013)

Craig, B., von Peter, G.: Interbank tiering and money center banks. J. Finan. Intermed. 23(3), 322-347 (2014)

Csardi, G., Nepusz, T.: The igraph software package for complex network research. Intern. J. Complex Systems 1695 (2006)

De Masi, G., Iori, G., Caldarelli, G.: Fitness model for the Italian interbank money market. Phys. Rev. E 74, 066112 (2006)

Drehmann, M., Tarashev, N.: “Measuring the systemic importance of interconnected banks," BIS Working Paper 342 (2011)

Durreé, A., Nardelli, S.: Volatility in the Euro area money market: Effects from the monetary policy operational framework. Int. J. Finan. Econ. 13(4), 307-322 (2008)

Easley, D., Hvidkjaer, S., O’Hara, M.: Is information risk a determinant of asset returns? J. Finan. 57(5), 2185-2221 (2002)

Easley, D., O’Hara, M.: Price, trade size, and information in securities markets. J. Finan. Econ. 19(1), 69-90 (1987)

ECB: Euro money market survey (2010)

Fecht, F., Nyborg, K.G., Rocholl, J.: "The price of liquidity: The effect of market conditions and bank characteristics," ECB Working Paper 1376 (2011)

Finger, K., Fricke, D., Lux, T.: Network analysis of the e-MID overnight money market: The informational value of different aggregation levels for intrinsic dynamic processes. Comput. Manag. Sci. 10(2-3), 187-211 (2013)

Freeman, L.: Centrality in social networks: conceptual clarification. Soc. Netw. 1, 215-239 (1979)

Fricke, D., Lux, T.: Core-periphery structure in the overnight money market: Evidence from the e-MID trading platform. Comput. Econ. 45, 359-395 (2015)

Gabrieli, S.: The functioning of the European interbank market during the 2007-08 financial crisis. CEIS Tor Vergata Research Paper Series, No. 158 (2009)

Gabrieli, S.: "Too-connected versus too-big-to-fail: Banks' network centrality and overnight interest rates", Bank of France Working Paper, N. 398 (2012)

Hatzopoulos, V., Iori, G., Mantegna, R.N., Micciche, S., Tumminello, M.: "Quantifying preferential trading in the e-MID interbank market,' Discussion paper (2013)

Heider, F., Hoerova, M., Holthausen, C.: "Liquidity hoarding and interbank market spreads: The role of counterparty risk," ECB Working Paper 1126, ECB (2009)

Holthausen, C., Pill, H.: The forgotten markets: How understanding money markets helps us to understand the financial crisis. ECB Research Bulletin No. 9 (2010)

Iazzetta, C., Manna, M.: 'The topology of the interbank market: Developments in Italy since 1990," Working Paper 711, Bank of Italy (2009a)

Iazzetta, C., Manna, M.: The topology of the interbank market: Developments in Italy since 1990. Banca d'Italia (2009b)

Idier, J., Nardelli, S.: Probability of informed trading on the euro overnight market rate. Int. J. Econ. Finan. 16(2), 131-145 (2011)

Iori, G., De Masi, G., Precup, O., Gabbi, G., Caldarelli, G.: A network analysis of the Italian overnight money market. J. Econ. Dyn. Control 32, 259-278 (2008)

Iori, G., Mantegna, R.N., Marotta, L., Micciche, S., Porter, J., Tumminello, M.: "Networked relationships in the e-MID interbank market: A trading model with memory," Unpublished manuscript. http://ssrn. com/abstract=2408952 (2014)

Kinne, B.J.: Multilateral trade and militarized conflict: Centrality, openness, and asymmetry in the global trade network. J. Politics 74(01), 308-322 (2012)

Kraenzlin, S., von Scarpatetti, B.: 'Bargaining power in the repo market," Swiss National Bank Working Paper, No. 14 (2011)

La Ganga, P., Vento, G.: 'Interbank market and liquidity distribution during the great financial crisis: The e-Mid case. J Money Invest Banking 18 (2010)

Lenza, M., Pill, H., Reichlin, L.: Monetary policy in exceptional times. Econ. Policy 25(4), 295-339 (2010) 
MacKenzie, M.: 'LIBOR probe shines light on voice brokers," Financial Times (2012)

Markose, S., Giansante, S., Gatkowski, M., Shaghaghi, A.R.: "Too interconnected to fail: Financial contagion and systemic risk in network model of CDs and other credit enhancement obligations of us banks," Analysis (2009)

Opsahl, T.: tnet: Software for analysis of weighted, two-mode, and longitudinal networks. R Package Version 2, 1 (2011)

Opsahl, T., Agneessens, F., Skvoretz, F.: Node centrality in weighted networks: Generalizing degree and shortest paths. Soc. Netw. 32(3), 245-251 (2010)

Opsahl, T., Panzarasa, P.: Clustering in weighted networks. Soc. Netw. 31(2), 155-163 (2009)

Ozsoylev, H., Walden, J.: Asset pricing in large information networks, Haas School of Business. University of California, Berkeley (2009)

Ozsoylev, H., Walden, J., Yavuz, M.D., Bildik, R.: "Investor networks in the stock market," in AFA 2012 Chicago Meetings Paper (2011)

Raddant, M.: Structure in the Italian overnight loan market. J. Int. Money Finan. 41(C), 197-213 (2014)

Soramaki, K., Bech, M.L., Arnold, J., Glass, R.J., Beyeler, W.E.: "The topology of interbank payment flows," Staff Report 243, Federal Reserve Bank of New York (2006)

Walden, J.: Trading, profits, and volatility in a dynamic information network model, Manuscript, Haas School of Business. University of California, Berkeley (2013)

Wasserman, S., Faust, K.: Social network analysis: Methods and applications, Structural analysis in the social sciences. Cambridge University Press, New York (1994)

Wycislik, L., Warchal, L.: Using Oracle $11.2 \mathrm{~g}$ database server in social network analysis based on recursive SQL. In: Computer Networks, pp. 139-143. Springer (2012)

Caterina Liberati received her Ph.D. in Statistics in 2006 from the University of Bologna, Italy. Since 2010, she has been an Assistant Professor in Statistics for Economy at the University of Milano-Bicocca, where she collaborates with the Bicocca Applied Statistics Center of Research. She has published more than 25 papers in refereed journals and international conferences in the fields of data mining, business, and economic statistics. Her current research interests include all aspects related to business analytics and applied statistics, particularly multidimensional modeling for economic applications and dynamic patterns.

Massimiliano Marzo is an Associate Professor of Economics at the University of Bologna, and Adjoint Professor of Financial Market Analysis and of Fixed Income Securities at Johns Hopkins University, SAIS, Bologna. He obtained his Ph.D. in Economics from Yale University. He is also a director of the Unifortune Asset Management Group. His research focuses on macroeconomic dynamics, economic policy, and market microstructure.

Paolo Zagaglia is an Assistant Professor of Economics at the University of Bologna. He earned a Ph.D. in Economics from Stockholm University. His previous engagements include visiting positions at the ECB, the Bank of England, the Bank of Finland, and a permanent appointment as economist at the Central Bank of Sweden. His current research focuses on financial market microstructure, portfolio management, and monetary policy.

Paola Zappa holds a Ph.D. in management from the University of Milano-Bicocca, where she also served as a postdoc in applied statistics. She is currently an SNSF postdoc fellow at the Faculty of Economics and at the Social Network Analysis Research Center, University of Italian Switzerland (CH). Her research interests lie in the domains of management and organizational theory, with a particular emphasis on intraand inter-organization collaboration networks. 